\title{
Autonomy-supportive teaching and its antecedents: differences between teachers and teaching assistants and the predictive role of perceived competence
}

\section{Marcus Bennett; Terry Ng-Knight; Ben Hayes}

\begin{abstract}
Research predicated on self-determination theory (SDT) has established a positive relationship between autonomy-supportive teaching and a range of desired student outcomes. Therefore, the enhancement of autonomy-supportive teaching is a legitimate focus of efforts to improve student outcomes. In this study we compared self-reported levels of autonomysupportive teaching among different educational professionals and explored the relationships between four hypothesised antecedents of autonomy support: constraints at work, perceived competence for teaching, perceptions of students' autonomous motivation towards school, and autonomous motivation for teaching. Questionnaire data from 429 teachers and teaching assistants (TAs) working in schools in the United Kingdom (UK) revealed that teachers report significantly more autonomy-supportive teaching than do TAs. Structural equation modelling indicated that the more teachers feel competent the more their teaching is autonomy-supportive. Among a range of other significant findings, teachers, but not TAs, who experience fewer constraints at work are more autonomously motivated towards teaching. The findings suggest that differences in autonomy-supportive teaching may account, at least in part, for the differential impact of teachers and TAs on academic progress as revealed by recent large-scale research in the UK. Furthermore, they identify social-contextual variables that should be considered when attempting to promote autonomy-supportive teaching and educators' motivation towards teaching.
\end{abstract}


Key Words Self-determination theory; autonomy support; perceived competence; autonomous motivation; pressure at work; teaching assistants.

\section{Bennett $(\bowtie)$}

Essex Educational Psychology Service, Causeway House, Bocking End, Braintree, Essex, CM7 9HB, United Kingdom

e-mail: marcus.bennett@essex.gov.uk

\section{T. Ng-Knight}

Educational Psychology Group, University College London, 26 Bedford Way, London, WC1H 0AP, United Kingdom

email: terry.ng-knight.11@ucl.ac.uk

URL: http://www.ucl.ac.uk/educational-psychology/

\section{B. Hayes}

Educational Psychology Group, University College London, 26 Bedford Way, London, WC1H 0AP, United Kingdom

email: b.hayes@ucl.ac.uk

URL: http://www.ucl.ac.uk/educational-psychology 
Within UK schools the term $\mathrm{TA}^{1}$ is used to describe paraprofessionals who provide support in relation to classrooms or particular students. Since 1997 one of the most striking changes in the UK education system has been the huge increase in the number of TAs, a role for which there is no minimum entry-level qualification (Blatchford et al. 2012). During the same period, similar, albeit less pronounced growth in the number of TAs has occurred in schools in the USA, Australia, South Africa and Hong Kong, as well as a host of European countries (Blatchford et al. 2012; Giangreco and Doyle 2007; Giangreco et al. 2010; Sharples et al. 2015). Before the Deployment and Impact of Support Staff (DISS) Project (Blatchford et al. 2009, 2012), unique both in terms of its scale and length, there had been little rigorous research into the characteristics, role, and impact of TAs; a group whose numbers grew in the belief that this would raise student standards, reduce excessive teacher workload, and promote inclusion for students with special educational needs and disabilities (SEND; Sharples et al. 2015). The DISS revealed that TAs have a direct pedagogical role and, worryingly, that students who receive increased TA support make less academic progress than similarly able peers (Blatchford et al. 2009, 2012).

Autonomous motivation, defined as "acting with a sense of full endorsement and volition" (Deci and Ryan, 2012, p. 85), is positively related to psychological wellbeing and effective performance (see Deci and Moller 2005; Deci and Ryan 1985, 2002, 2012) including in the context of education (see Niemiec and Ryan 2009). Such an interactional style is opposed to controlled motivation, a state in which people feel pressured to behave in certain ways and which can lead to a lack of intentionality, or amotivation (Deci and Ryan 2012). This study examines whether the negative effect of TA support on attainment as evidenced in Blatchford et al. (2009, 2012) could in part reflect TAs' more controlling interactional style relative to a more autonomy-supportive style adopted by teachers. In addition, it explores the relationships between four hypothesised antecedents of autonomy support.

\section{Teaching Assistants and the Deployment and Impact of Support Staff (DISS) Project}

The DISS project's most disturbing discovery was clear: students who received more support from TAs engaged less with a qualified teacher and made significantly less academic progress than similar students who had received less TA support (Webster et al. 2013). To account for these findings Blatchford et al. (2012) created the Wider

\footnotetext{
${ }^{1}$ As in Webster et al. (2013), the term 'teaching assistant' (TA) is used throughout to cover equivalent or similar classroom-based support staff, alternatively called 'classroom assistants', 'learning support assistants' or 'higher level teaching assistants'.
} 
Pedagogical Role (WPR) model (see also Webster et al. 2011). The WPR comprises three main components posited to determine the effectiveness of TAs at the respective levels of school, classroom and student. Preparedness refers to the training and professional development received by teachers and TAs as well as day-today preparation including the opportunities available to teachers and TAs for joint planning, preparation and feedback. Deployment refers to the professional activities in which TAs engage. Practice refers to the nature of the interactions TAs have with students.

In terms of TAs' practice, Blatchford et al. (2012) identified differences in the types of interactions that TAs have with students compared to those that occur between teachers and students. Radford et al. (2011) summarised these as the difference between "opening up and closing down" (p. 625). Teachers' talk was characterised by 'open' strategies including open questions, asking students what they thought, and providing hints and prompts when students require help. TAs, on the other hand, were more likely to use closed questions, provide students with answers, and focus on task completion over learning. Describing the TA role as one that is primarily oral, Radford et al. (2011) discussed the negative implications for students' learning of working with TAs whose verbal interactions ““close down' students, both linguistically and cognitively” (p. 632).

In Blatchford et al. (2012) the quality of teachers' and TAs' practice was measured against Berliner's (1987) model of effective teaching. Rather than disputing that teachers' and TAs' interactions differ in quality, the present study argues that this difference is characterised by the extent to which the professional groups are controlling or autonomy-supportive in their interactions. Table 1 defines controlling and autonomy-supportive behaviour and gives examples of the types of instructional behaviours associated with each. From this it is clear that teachers' and TAs' behaviours as identified by Blatchford et al. (2012) and Radford et al. (2011) can be categorised as either controlling or autonomy-supportive. Specifically, there is a clear distinction by which TAs' talk tends to be controlling while teachers' talk is more autonomy-supportive. For example, when teachers explain concepts and ask open questions they are providing explanatory rationales, using informational language and allowing time for students to learn at their own pace. In contrast, TAs' focus on task completion is an example of 'impatience for students to produce the right answer'. Given the positive relationship between autonomysupportive teaching and a range of desired student outcomes (Guay et al. 2008; Reeve 2009; Soenens et al. 2012), SDT represents an appropriate framework for enhancing our understanding of TAs' practice and impact as well as extending the extant literature on teacher effectiveness.

\section{Self-determination theory}


Self-determination theory (SDT) is a meta-theory of human motivation and personality (Deci and Ryan 1985, 2002, 2012; Ryan and Deci 2000a, 2000b). It posits that motivation is central to human functioning and distinguishes between six types of motivation ranging from amotivation to intrinsic motivation, as ordered along a continuum of perceived autonomy (Deci and Ryan 2000, 2012; Deci and Moller 2005; Ryan and Connell 1989; Ryan and Deci 2000a, 2003). Research has demonstrated that with greater autonomy comes increased positive psychological wellbeing and effective performance (see Deci and Moller 2005; Deci and Ryan 1985, 2002, 2012), including within education (see Guay et al. 2008; Niemiec and Ryan 2009; Reeve, 2009).

When teachers promote student autonomy, students experience greater autonomous motivation for learning (Roth et al. 2007; Vallerand et al. 1997) and, in turn, achieve better outcomes (Guay et al. 2008; Reeve 2009; Soenens et al. 2012). Autonomy-supportive teaching has been defined as an interpersonal style that promotes volition, interest, and a sense of initiative in others (Soenens et al. 2012).

Pelletier et al. (2002) proposed and tested a framework that organised multiple influences thought to affect the extent to which teachers adopt either a controlling or autonomy-supportive style. Based on data from 254 Canadian teachers of students in Grades 1 to 12 they found that the more pressure teachers experienced, from both above (i.e., a pressurised school environment) and below (i.e., the extent to which they perceived their students not to be autonomously motivated towards school), the less autonomous motivation they experienced and, in turn, the more controlling they were with their students. These results have since been replicated in the context of sports coaching (Rocchi et al. 2013). Similarly, Roth et al. (2007) found a positive association between teachers' self-reported autonomous motivation for teaching and their autonomy-supportive teaching, as reported by their students (Grades 3 to 6). In a sample of 488 teachers of adolescent students in Grades 11 and 12, Soenens et al. (2012) found that teachers who experienced greater autonomous motivation for teaching reported less psychologically controlling teaching with this relationship mediated by depersonalization, a component of burnout (see Friedman 1995; Maslach et al. 2001). Though similar, and in each case underpinned by SDT, the measures used to operationalize key constructs in these studies differed and, in the case of Soenens et al. (2012), it is important to note the distinction between psychologically controlling teaching and autonomy-supportive teaching. Recent research has demonstrated that, rather than representing opposite ends of the same continuum, autonomysupportive and controlling interactional styles have distinct antecedents (Stebbings et al. 2012) reflecting the related distinction between individuals' experience of need satisfaction and need thwarting (see Bartholomew et al. 2011; Vansteenkiste and Ryan 2013). While acknowledging that differences pertaining to their samples, 
measures and constructs mean caution is necessary when comparing across studies, the present study, by adopting SDT as its theoretical framework, builds on existing information regarding the antecedents of autonomy support among teachers and extends this to TAs, who themselves have a direct pedagogical role.

\section{Summary of the present study and hypotheses}

The present study replicated the work of Pelletier et al. (2002), extending it in three ways. Firstly, it replicates the study within a contemporary UK context.

Secondly, it proposes an additional antecedent of autonomy support not considered by the previous research described. This antecedent is perceived competence for teaching. Perceived competence is defined as an individual's belief in their ability to meet the challenges of a task (Niemiec and Ryan 2009). It is regarded in SDT as one of three basic psychological needs without which individuals cannot experience more autonomous forms of motivation (Deci and Ryan 1985, 2002, 2012; Ryan and Deci 2000a, 2000b). As illustrated by Guay et al. (2001), the relationships and, particularly, the causal sequences between autonomy, competence, and more autonomous forms of motivation are not yet clearly established. A number of studies have indicated that feelings of competence may be necessary to experience autonomy, and vice-versa, and that both predict intrinsic motivation (as described in reviews by Deci et al. 1999; Niemiec and Ryan, 2009; see also Radel et al. 2013). However, the authors are unaware of any studies that have examined whether perceived competence for teaching predicts either autonomous motivation for teaching or autonomy-supportive teaching. If such a relationship were shown to exist, then efforts to promote perceived competence would offer a means by which to affect the behaviour of educators and, in turn, student outcomes.

The hypothesized relationships between the study variables are illustrated in Figure 1. Following Pelletier et al. (2002) it was predicted that constraints at work would be negatively associated with autonomy-supportive teaching, whereas perceptions of students' motivation towards school were predicted to be positively associated with autonomy-supportive teaching. It was also predicted that both of these associations would be mediated by autonomous motivation for teaching. The link between teachers' autonomous motivation for teaching and autonomy support is well-established (Pelletier et al. 2002; Roth et al. 2007; for a review see Reeve 2009), as is the negative relationship between teachers experience of constraints at work and their autonomous motivation for teaching (Pelletier et al. 2002; Soenens et al. 2012; for a review see Reeve 2009). In contrast, evidence for the relationship between teachers' perceptions of their students' motivation towards school and teachers' autonomous 
motivation for teaching is equivocal, with Pelletier et al. (2002) and others (see Reeve 2009) having demonstrated such a link while others have not (Soenens et al. 2012). Finally, we hypothesized that perceived competence would predict autonomy support and that this relationship would be mediated by autonomous motivation for teaching. Though the present study is the first to consider perceived competence for teaching as an antecedent of autonomy support, this hypothesis is based on a wealth of research demonstrating that perceived competence predicts autonomous motivation in a range of contexts including education (Deci and Ryan 1985, 2000a; Goudas et al. 1995; Jang et al. 2009; Kalaja et al. 2009; Standage et al. 2003)

The third and final difference between the present study and Pelletier et al.'s (2002) is that the present study explores the relationships between autonomy-supportive teaching and its antecedents among TAs as well as teachers. Given the prominence of TAs within UK schools and their direct pedagogical role, any comprehensive understanding of autonomy support in classrooms would necessarily include information regarding TAs' behaviour. On the basis of the findings by Blatchford et al. (2012; Radford et al. 2011) regarding differences in teachers' and TAs' talk and the reframing of these differences as teachers' and TAs' respective propensity towards autonomy-supportive and controlling behaviour, we hypothesized that teachers would report more autonomysupportive teaching than TAs. Given the scarcity of research into the role and impact of TAs and the complete lack of research considering TAs' work from a motivational perspective, the predicted relationships between the study variables for TAs are the same as for teachers. It therefore follows that we predict that differences between the professional groups in terms of autonomy-supportive teaching will be accounted for by mean-level differences between teachers and TAs on the remaining four study variables. Specifically, teachers will score higher than TAs on those study variables predicted to be positively associated with autonomy support, namely autonomous motivation for teaching, perception of students' motivation towards school and perceived competence for teaching, and lower than TAs on those predicted to be negatively associated, namely constraints at work. Given the lack of previous research on the relationship between perceived competence and autonomy support for teachers and between autonomy support and the remaining study variables for TAs, a partially mediated model similar to that included in Pelletier et al. (2002) was also tested.

Fig. 1 Proposed mediated (top) and partially mediated (bottom) models of teachers' and TAs' autonomy support Note For the sake of simplicity, the word 'autonomous' has been removed twice from where the word 'motivation' appears while the phrase 'perceived competence' refers to 'perceived competence for teaching'. A '+' symbol 
denotes a positive relationship and a '-' symbol a negative relationship. Straight single-headed arrows represent hypothesised causal paths, while doubled-headed arrows are hypothesised correlations.

\section{Method}

Participants and procedure

Participants were 202 teachers (78\% females) and 227 TAs (90\% females) recruited from a total of 22 schools across the South-East of England. Participants worked across the range of UK mainstream educational settings; namely, infant (5-6 years; 9\%), junior (7-11 years; 36\%), and secondary schools (11-16 years; 37\%). The remaining participants were employed in government-funded nursery settings schools (3-4 years; 6\%) or in one special school for children and young people, the majority of whom have a diagnosis of autism spectrum disorder (7-19 years: 12\%). Questionnaires were administered in participants' schools by the lead researcher.

\section{Measures}

As well as completing the measures described below, participants were asked to respond to items regarding their age, sex, current professional role (teacher or TA), the number of years they had been working in this role, and the educational setting in which they spent the majority of their time at work.

Autonomous motivation for teaching Autonomous motivation for teaching was measured with the Autonomous Motivation for Teaching Scale (AMTS; Roth et al. 2007). Informed by SDT, this 16-item scale distinguishes between different motivation types along a continuum of perceived autonomy (Ryan and Connell 1989). Moving from most to least autonomous, the AMTS assesses four motivation types presented as individual four-item subscales: intrinsic motivation, identified regulation, introjected regulation, and external regulation. Each item is answered on a five-point scale ranging from 1 ("Not at all true") to 5 ("Very True"). Scores for each item are multiplied by either 3 (intrinsic motivation), 1 (identified regulation), -1 (introjected regulation) or -3 (external regulation) depending on which motivational construct they reflect. This results in negative scores for both the introjected and external regulation subscales. Scores are then added to produce a total score with higher scores indicating greater autonomous motivation for teaching. This process of weighting scale scores is described in 
Patrick et al (1993) and has been used in a range of other studies that have used indices of self-determination including Pelletier et al. (2002), Roth et al. (2007) and Soenens et al. (2012). Roth et al. (2007) reported acceptable internal consistency coefficients of between .68 and .76 for the four subscales.

In the present study, principal components analysis (PCA) revealed that the AMTS did not adhere to the predicted four-factor structure demonstrated in Roth et al. (2007) and therefore the identified and introjected regulation subscales were removed (see Appendix A). The retained intrinsic motivation and external regulation scales both showed satisfactory internal consistency $(\alpha=.64)$. For the purpose of assessing between-group differences these subscales were aggregated with the overall scale demonstrating satisfactory internal consistency $(\alpha=.67)$. In the final models, individual scale items were included as indicators of the latent construct, autonomous motivation for teaching, with correlated error variances added for items within subscales (see Brown 2006; further discussion is included in the Results).

Autonomy-supportive teaching Autonomy-supportive teaching was measured using a subscale from The Teacher as Social Context (TASC) scale (Wellborn et al. 1992; Skinner and Belmont 1993). The autonomy support subscale (TASCASS) comprises 12 items used to assess self-reported autonomy-supportive teaching among teachers and TAs. These 12 items are further divided into four subscales each comprising three items representing the four dimensions of autonomy support: controlling behaviour, respect, choice, and relevance (Wellborn et al. 1992). Each item is answered on a four-point scale ranging from 1 ("Not at all true") to 4 ("Very true") with higher scores indicating increased autonomy-supportive teaching. Wellborn et al. (1992) reported acceptable internal consistency for the TASCASS of .79.

In the present study, the three subscales of controlling behaviour $(\alpha=.78)$, respect $(\alpha=.69)$, and choice $(\alpha=.64)$ showed satisfactory internal consistency. The relevance subscale was removed from subsequent analyses due to poor internal consistency $(\alpha=.02)$. As with the AMTS, for the purpose of assessing between-group differences scores on the three subscales were aggregated with the overall scale demonstrating good internal consistency $(\alpha=.77)$. Similarly, in the final models individual scale items were included as indicators of the latent construct, autonomy-supportive teaching, with correlated error variances added for items within subscales (see Brown 2006; further discussion is included in the Results).

Constraints at work Constraints at work were measured using the Constraints at Work Scale (CWS) developed by Pelletier et al. (2002). This 9-item scale was designed to measure teachers' perceptions of three sources of 
constraints or pressure experienced at work: pressure from colleagues, school management and the curriculum. Each item is answered on a seven-point scale ranging from 1 ("Do not agree at all") to 7 (“Agree very strongly"). Higher scores indicate a higher perception of constraints at work.

In the present study, the three subscales relating to pressure from colleagues $(\alpha=.46)$, school management $(\alpha=.39)$, and the curriculum $(\alpha=.26)$ each had poor internal consistency. Similar findings were reported by Leroy et al. (2007) who therefore used a composite scale containing a reduced number of items. Following this precedent, three low-loading items (see Appendix A) were removed to create a unitary 6-item scale comprising two items from each of the original three subscales. The unitary 6-item scale demonstrated good internal consistency $(\alpha=$ .72).

Perception of students' autonomous motivation towards school Perceptions of students' motivation towards school were measured using The Perception of Students' Motivation Scale (PSMS: Pelletier et al. 2002). This 16-item scale was used to ask teachers and TAs why they believe students generally attend school. The 16 items are grouped into the same four subscales as in the AMTS. Each item is answered on a seven-point scale ranging from 1 ("Do not agree at all") to 7 ("Agree very strongly"). As described in relation to the AMTS, scores for each item are weighted according to the different motivational constructs they reflect ${ }^{2}$. Higher scores indicate that teachers' or TAs' perceive students to be more autonomously motivated towards school. Pelletier et al. (2002) reported acceptable internal consistency of .78 for the entire scale.

\footnotetext{
2 The PSMS assigned different weights to items from each of the four subscales compared to the AMTS. Specifically, items belonging to the intrinsic motivation and external regulation subscales are multiplied by 2 and -2 , respectively, while items belonging to identified and introjected regulation subscales are multiplied by 1 and 1, respectively. Other studies using these scales do not justify why different weights are used or explain the purpose, but the result of this weighting strategy is that more extreme forms of motivation (i.e., external and intrinsic) have a stronger influence on participants' scores. Nevertheless, the different weighting strategies used for the PSMS and AMTS have no influence on the results we present for three reasons (i) no comparisons are made between the two variables, (ii) because the use of standardised regression coefficients makes the raw metric of the measures arbitrary and (iii) because the identified and introjected regulation subscales were not included in the final analyses and therefore relative differences were cancelled out when final scales were summed.
} 
PCA revealed that the PSMS did not adhere to the predicted four-factor structure (see Appendix A). Therefore, as with the AMTS, the identified and introjected regulation subscales were removed. The retained intrinsic motivation $(\alpha=.85)$ and external regulation $(\alpha=.91)$ scales showed good internal consistency, as did the overall scale $(\alpha=.90)$. As described in relation to the AMTS and TASCASS, subscales scores were aggregated for the purpose of assessing between-group differences with individual items included as indicators of the latent construct within the final models.

Perceived competence for teaching Perceived competence for teaching was measured using an adapted version of the Perceived Competence Scale (PCS; "Perceived Competence Scales" n.d.). This version was named the Perceived Competence for Teaching Scale and was developed for the purpose of the present study.

The PCS was designed to assess individuals' perception of their competence for specific behaviours. It is composed of three items that could be applied to any occupation (e.g. "I feel confident in my ability to do my job") and two items that are adapted to fit the specific behaviour of interest (e.g. "I am capable of getting children to succeed at school"). Each item is answered on a seven-point scale ranging from 1 ("Not at all true") to 7 ("Very true"). Higher scores indicate greater perceived competence for teaching. The PCS is generally regarded as having excellent face validity ("Perceived Competence Scales" n.d.) and, like previous studies using different versions of the PCS, the PCTS was found to have high internal consistency $(\alpha=.88)$.

\section{Results}

Preliminary analyses

Data screening Following guidance from Tabachnick and Fidell (2007) the data was found to meet the assumptions of multivariate analyses in relation to normal distribution, linearity, homoscedasticity, multicollinearity and singularity.

Bivariate correlations for all study variables are presented in Table 2. For teachers, all significant correlations were in the predicted direction. For TAs, three significant correlations were unexpected. These were the positive correlation between TAs' respect for students (a subscale of the AMTS) and their external regulation towards teaching, as well as the finding that TAs' controlling behaviour was positively correlated with intrinsic motivation for teaching and negatively correlated with external regulation for teaching. As intrinsic motivation 
and external regulation are at opposite ends of the continuum of relative autonomy we would expect predictors such as controlling behaviour to be positively related with one of these indicators and negatively correlated with the other. Therefore, that these correlations have opposite signs is unsurprising however they are both in the opposite direction to our hypotheses. As described below in the section on the Measurement model, subsequent analyses using structural equation modelling (SEM) used a latent variable to represent a continuous scale of autonomous motivation for teaching where high scores indicate high autonomous motivation; that is, high intrinsic motivation and low external regulation. For TAs, all other correlations were in the predicted direction.

Control variables Following Soenens et al. (2012), analysis using MANOVA examined differences on the main study variables using the demographic variables as between-subject variables (for the univariate PCTS and CWS, ANOVA was used). An overall significant effect was found for gender on autonomous motivation for teaching $\left(\right.$ Wilks' $\left.\lambda=0.93 ; F(1,400)=7.52 ; p<.001, \eta^{2}=.07\right)$, while a significant effect was found for educational setting on all study variables: autonomous motivation for teaching (Wilks' $\lambda=0.91 ; F(4,397)=2.46 ; p<.01, \eta^{2}=.02$ ); autonomy-supportive teaching (Wilks' $\left.\lambda=0.77 ; F(4,397)=6.18 ; p<.001, \eta^{2}=.06\right)$; constraints at work $(F(4$, $\left.397)=6.10 ; p<.001, \eta^{2}=.06\right) ;$ perceptions of students' autonomous motivation towards school (Wilks' $\lambda=0.66$; $\left.F(4,397)=11.10 ; p<.001, \eta^{2}=.10\right)$; perceived competence for teaching $\left(F(4,397)=2.67 ; p<.01, \eta^{2}=.04\right)$. Therefore gender and educational setting were included as controls in the subsequent analyses.

Primary Analyses

Between-group differences for autonomy-supportive teaching As predicted, teachers reported offering significantly more autonomy support than TAs $(t(400)=5.32, p<.001, d=.53)$ with the difference representing a medium effect (in accordance with Cohen 1988). Scores on the individual subscales indicate that teachers reported offering students more choice $(t(400)=4.53, p<.001, d=.45)$ and respect $(t(400)=1.98, p<.01, d=$ $.21)$ as well as using less controlling behaviour $(t(400)=5.17, p<.001, d=.51)$. Means, standard deviations and role differences for all study variables are presented in Table 3.

Measurement model An initial measurement model was tested to assess whether the indicators evaluated the latent constructs accurately. The initial model comprised five latent constructs: autonomous motivation for teaching, autonomy-supportive teaching, constraints at work, perceptions of students' autonomous motivation towards 
school, and perceived competence for teaching. In addition, gender and educational setting were each included as latent variables with single indicators, the error variance of which was set to 0. Following guidance from Byrne (2010) and Kline (2011), multiple criteria were used to assess model fit. The root-mean-square error of approximation (RMSEA) and the comparative fit index (CFI) in addition to chi-square $\left(\chi^{2}\right)$. On account of the limitations of $\chi^{2}$ (see Byrne 2010), a RMSEA equal to or lower than .08 (Hu and Bentler 1999) and a CFI >.90 (Byrne 1994) have been suggested as indicative of acceptable fit.

Analyses were run using Amos (Version 21, Arbuckle and Wothke 1999) maximum likelihood fitting function. The initial measurement model was rejected on the grounds of poor fit for both teachers, $\chi^{2}(896)=$ 2307.70, $p<.001 ;$ RMSEA $=0.09$, RMSEA Confidence Interval $(\mathrm{CI})[.08, .10]$; CFI $=.47$, and TAs, $\chi^{2}(896)=$ 2672.47, $p<.001$; RMSEA $=0.10$, RMSEA CI $[.09, .10]$; CFI $=.49$. On the basis of these results, the initial measurement model was rejected and the model respecified. As described by Joreskog (1993), respecification is an exploratory approach where, having rejected an initial theoretically justified model on the basis of poor fit, the researcher modifies the model according to theory or the data so as to find a model that both fits the data and is substantively meaningful. Following guidance from Hooper et al. (2008), the fit of each construct was assessed separately using exploratory factor analytic procedures (see also Browne 2001). The only changes made involved the drawing of error covariances between items that belonged to the same subscale or which, belonging to the same scale, overlapped to a high degree as indicated by values for modification indices (see Byrne 2010). These changes were informed by Brown (2006) who describes the implications of choosing to account for the additional covariance between two indicators using error covariance within a unidimensional structure rather than by adding an additional latent factor. Following these changes, the final measurement model provided reasonable fit to the data for TAs, $\chi^{2}(559)=839.29, p<.001$; RMSEA $=.05,90 \%$ RMSEA CI $[.04, .06]$; CFI $=.91$, and was approaching reasonable fit for teachers, $\chi^{2}(559)=853.43, p<.001$; RMSEA $=.05,90 \%$ RMSEA CI [.05, .06]; $\mathrm{CFI}=.87$

Mediated model of teachers' and TAs' autonomy-supportive teaching For teachers, the model was approaching reasonable fit with the data. Although the chi-square statistic was significant and the CFI fell short of .90 (Byrne 1994), the RMSEA of .05 indicated good fit (MacCallum et al. 1996), $\chi^{2}(562)=865.76, p<.001 ; \operatorname{RMSEA}=.05$, $90 \%$ RMSEA CI $[.05, .06] ; \mathrm{CFI}=.87$.

Three of the four structural paths were significant (see Figure 2). As predicted, the more teachers perceived themselves to be competent at teaching, the more they experienced autonomous motivation towards 
teaching. Based on Cohen (1988), the size of this effect was medium $(\beta=.35, p<.01)$. Similarly, the less pressure teachers felt at work the more autonomously motivated towards teaching they were, with a medium to large effect $(\beta=-.46, p<.01)$. Contrary to predictions, the more teachers perceived their students to be autonomously motivated towards school the less autonomously motivated towards teaching they were. The size of this effect was small $(\beta=-.20, p<.05)$. Having predicted that autonomous motivation towards teaching would be positively related to autonomy-supportive teaching no significant relationship was found $(\beta=.17, p>.05)$. Finally, higher levels of competence were associated with fewer constraints at work, with a small to medium effect $(\beta=-.35, p<$ $.01)$.

There was better fit for the mediated model among TAs. Although the chi-square statistic was significant, reasonable fit was indicated by both the CFI and RMSEA, $\chi^{2}(562)=847.90, p<.001 ; \mathrm{RMSEA}=.05,90 \%$ RMSEA CI $[.04, .06]$; CFI $=.91$. However, only one of the four structural paths was significant. As was the case among teachers, the more TAs perceived themselves to be competent at teaching the greater their autonomous motivation towards teaching. This effect was small $(\beta=.24, p<.05)$. As there was among teachers, there was a negative correlation between TAs' perceived competence and their experience of constraints at work, in this case, with a medium effect $(\beta=-.32, p<.001)$.

Multi-group analysis was conducted to compare the strength of the associations between variables for teachers and TAs for the mediated model (see Table 4). The only significant difference was for the relationship between perceived constraints at work and autonomous motivation for teaching.

Fig. 2 Mediated model with standardised estimates for the relations among the latent variables $* p<.05 ; * * p<.01 ; * * * p<.001$

Note Standardised coefficients are shown with estimates for teachers presented on the left and estimates for TAs presented on the right. Model also controls for gender effects on autonomous motivation for teaching and setting effects on all variables.

Partially mediated model of teachers' and TAs' autonomy-supportive teaching Following the steps taken in Pelletier et al. (2002) a partially mediated model was tested. Although the failure to demonstrate a relationship between autonomous motivation for teaching and autonomy support means there is no mediation, the addition to the mediated model of direct paths from each of the three predictor latent variables (constraints at work, 
perceptions of students motivation towards school, perceived competence for teaching) permitted an assessment of whether these variables explain unique variance in autonomy-supportive teaching.

The partially mediated model was approaching reasonable fit for teachers, $\chi^{2}(559)=853.55, p<.001$; RMSEA $=.05,90 \%$ RMSEA CI $[.05, .06] ; \mathrm{CFI}=.87$, and demonstrated reasonable fit for TAs, $\chi^{2}(559)=839.14$, $p<.001$; RMSEA $=.05,90 \%$ RMSEA CI $[.04, .06] ;$ CFI $=.91$. For teachers, it revealed a significant positive effect of perceived competence on autonomy-supportive teaching $(\beta=.34, p<.001)$, indicating that the more competent teachers felt the more autonomy support they reported offering their students (see Figure 3 ). There were no significant direct effects between either of the other exogenous variables and autonomy-supportive teaching. This was also the case for TAs, for whom there was no significant direct effect of perceived competence on autonomy-supportive teaching.

As with the mediated model, multi-group analysis was conducted to compare the strength of the associations between variables for teachers and TAs (see Table 4). Again, the only significant difference was for the relationship between perceived constraints at work and autonomous motivation for teaching. The relationship between perceived competence and autonomy support was approaching significance $(p=.05)$.

Fig. 3 Partially mediated model with standardised estimates for the relations among the latent variables $* p<.05 ; * * p<.01 ; * * * p<.001$

Note Standardised coefficients are shown with estimates for teachers presented on the left and estimates for TAs presented on the right. Model also controls for gender effects on autonomous motivation for teaching and setting effects on all variables.

Summary of results

In summary, the mediated model fit the data well for TAs and was approaching reasonable fit for teachers. The amount of variance explained in teachers' (13\%) and TAs' autonomy-supportive behaviour (2\%) was small, although it was higher for teachers' $(66 \%)$ and TAs' $(15 \%)$ autonomous motivation towards teaching. Path coefficients revealed that in neither group was there evidence of a significant relationship between autonomous motivation towards teaching and autonomy-supportive teaching. However, significant effects were found indicating that when teachers feel less pressure at work they are more autonomously motivated towards teaching. In addition, the more teachers and TAs perceive themselves to be competent at teaching the greater their 
autonomous motivation towards teaching. Finally, results from the partially mediated model indicated that among teachers greater feelings of competence predict increased autonomy-supportive teaching.

\section{Discussion}

The present study applied SDT, a meta-theory of human motivation and personality ("About the theory" n.d.; Deci and Ryan 2012), to practice in UK schools. This discussion is organised around the findings in relation to its two primary hypotheses.

Autonomy-supportive teaching: differences between teachers and TAs

As hypothesized, we found that teachers reported significantly greater autonomy-supportive teaching than TAs. Recent research in the UK highlighted differences in the quality of teacher and TA talk (Radford et al. 2011). These differences were characterised as TAs' tendency to “cclose down' students, both linguistically and cognitively" (p. 632) compared to teachers' ability to 'open them up'. The findings from the present study support an alternative distinction: compared to TAs, teachers adopt a more autonomy-supportive as opposed to controlling interactional style. Autonomy-supportive teaching refers to an interpersonal style that promotes volition, interest, and a sense of initiative in others (Soenens et al. 2012) and which is positively related to academic achievement (Jang et al. 2012; Soenens et al. 2012; for reviews see Guay et al. 2008; Reeve 2009). On this basis, we propose that the negative effect of TA support on academic progress as identified by Blatchford et al. (2012) is partly attributable to TAs being more controlling. Importantly, the present study, like the study conducted by Blatchford et al. (2012), does not test the direct relationship between teacher- and TA-student interactional styles and academic achievement. Nonetheless, the findings suggest this relationship is worthy of further consideration given its implications for practice in schools.

Antecedents of autonomy-supportive teaching

The study also tested the relationships between autonomy support and four proposed antecedents, each of which are associated with individuals' basic psychological needs according to SDT. Our hypotheses regarding the relationships between autonomy support and three of the proposed antecedents were based on those identified in 
Pelletier et al. (2002). As an addition to the model tested by Pelletier et al. (2002) we included perceived competence for teaching. Feelings of competence represent one of three basic psychological needs that determine the extent to which individuals experience autonomous motivation (Deci and Ryan 1985, 2002, 2012; Ryan and Deci 2000a, 2000b). With autonomous motivation for teaching having been shown to predict autonomy-supportive teaching (Pelletier et al. 2002; Roth et al. 2007; see also Reeve 2009), we predicted that perceived competence would predict autonomy support with this relationship being mediated by autonomous motivation for teaching.

The most surprising finding was that autonomous motivation for teaching was not significantly related to autonomy support among teachers or TAs. In addition to Pelletier et al.’s (2002) findings, Roth et al. (2007) found that teachers who were more autonomously motivated towards teaching offered students greater autonomy support, while Soenens et al. (2012) found that autonomous motivation for teaching was negatively related to psychologically controlling as mediated by teachers' feelings of depersonalisation. A possible explanation for this surprising finding relates to geographic and temporal factors that distinguish the present study from those previously conducted. In the years since the publication of the studies by Pelletier et al. (2002) and Roth et al. (2007) there has been an increased emphasis in the UK on teachers adopting practices that might reasonably be regarded as autonomy-supportive as part of a drive towards students becoming better able to take responsibility for their own learning. For example, a decade ago a report published by the Department for Education and Skills (2006; see also Department for Children, Schools and Families 2008) outlined a clear vision for the future of teaching whereby teachers should focus on creating active, curious learners who "create their own hypotheses, ask their own questions, coach one another, set goals for themselves, monitor their progress and experiment with ideas for taking risks" (p. 5). The parallels between such an approach and the list of instructional behaviours associated with autonomy support are clear (see Table 1). With all UK teachers having been instructed to adopt autonomysupportive practice the degree to which socio-contextual factors including teachers' motivational dispositions account for variance in their autonomy support is likely to have reduced.

A possible exception to the above would be the relationship between teachers' perceived competence for teaching and their autonomy support. This is due to teachers' perceptions of their competence being likely to be at least partly based on their beliefs regarding their ability to meet externally defined criteria such as the aforementioned government documents recommending teaching practices aligned with autonomy support. As a result, the extent to which teachers perceive themselves to be competent would be positively related to their perceptions of their ability to demonstrate autonomy-supportive behaviours. This was perhaps borne out in the present study, the most striking finding of which was a direct positive relationship between teachers' perceived 
competence for teaching and the autonomy support they offered their students. For TAs, no significant relationship between perceived competence for teaching and autonomy support was found and the difference between teachers and TAs almost reached statistical significance giving us some confidence that this relationship is stronger amongst teachers than TAs. However, the fact that TAs reported significantly lower autonomy-supportive practice than teachers could reflect the support that teachers, but not TAs, will have received to be able to adopt the types of practices outlined in government guidance such as through pre- and in-service training. These training opportunities will almost certainly have been unavailable to the vast majority of TAs in the UK who Blatchford et al. (2012) found typically receive little training either in role or prior to taking up their position.

Among both teachers and TAs, perceived competence was positively associated with autonomous motivation for teaching while, consistent with previous research (Pelletier et al. 2002; Soenens et al. 2012), teachers who reported experiencing fewer constraints at work were more autonomously motivated towards teaching. For TAs this relationship was weaker and non-significant, though it did not differ significantly to teachers. As in Pelletier et al. (2002), the partially mediated models revealed no direct relationship between constraints at work and autonomy-supportive teaching. These findings provide further support for one of the central tenets of SDT: feelings of autonomy and competence are necessary for individuals to experience autonomous forms of motivation (Deci and Ryan 1985, 2002, 2012; Ryan and Deci 2000a, 2000b). In the case of the relationship between constraints at work and autonomous motivation, the present study offers further evidence of the importance of reducing constraints on teachers if they are to experience positive forms of motivation (Pelletier et al. 2002; Soenens et al. 2012). A possible explanation for no such relationship having been found among TAs may reflect what Vansteenkiste et al. (2012) refer to as the interplay between autonomy support and structure. Guay et al. (2008) define structure as communicating to others what is expected of them and describe how structure can be provided in either an autonomy-supportive or a controlling way. Vansteenkiste et al. (2012) describe how autonomy support and structure are mutually supportive and have been shown to co-vary positively. For example, Sierens et al. (2009) found a positive effect on students' self-regulation of perceived teacher structure only when students also perceived sufficient levels of teacher autonomy support. If extended to the psychological environment in which TAs function, this interplay between autonomy and structure could explain why the constraints experienced by TAs do not appear to determine their autonomous motivation. Specifically, it is plausible that without sufficient structure, autonomy, measured here in terms of perceived constraints at work, will not relate to autonomous motivation. The analysis by Blatchford et al. (2012) of the way in which TAs are deployed 
in schools supports this explanation as they found little clarity as to what is expected of TAs; that is, there role lacks structure.

With regard to the final proposed antecedent of autonomy-supportive teaching, findings from the present study resemble those in Soenens et al. (2012) rather than Pelletier et al. (2002). Specifically, there was no evidence of a positive relationship between teachers' perceptions of students' motivation for learning and their autonomous motivation for teaching or autonomy-supportive teaching. In fact, teachers who thought students were more autonomously motivated towards school were likely to have lower autonomous motivation for teaching. There was no evidence that TAs' perceptions of students' motivation for learning predicted either their own autonomous motivation for teaching or their autonomy-supportive teaching. Soenens et al. (2012) attribute their failure to find a relationship between teachers' perception of students' motivation and psychologically controlling teaching to the fact that students' controlled motivation would not necessarily impact on the person teaching them as the students may nonetheless be compliant. However, studies included in Reeve's (2009) review of research on teachers' interactional style suggest that autonomy support is affected by this type of pressure from below. A possible explanation for variation in the studies' findings may lie in differences in terms of the participants they included. For example, Soenens et al. (2012) included adolescent students in grades 11 and 12 while the present study comprised $37 \%$ in secondary education. In contrast, the studies reviewed by Reeve (2009) include only adult participants (Pelletier and Vallerand 1996; Reeve and Jang 2006) and younger students (Skinner and Belmont 1993). While Pelletier et al. (2002) do not provide additional information regarding the age of participants the fact that they are all in grades $1-12$ does not preclude a significant proportion being much younger than in Soenens et al. (2012) and the present study. It is therefore possible that the positive relationship between teachers' perceptions of their students' autonomous motivation towards school and teachers' autonomous motivation for teaching may exist only among adults and younger students, rather than among adolescents.

Summary of implications for educational practice

On account of the beneficial correlates of autonomy-supportive teaching, the finding that TAs provide less autonomy support than teachers has two important implications for educational practice. Firstly, TAs, if they are to continue to have a direct pedagogical role, should receive support to develop more autonomy-supportive practice. As Blatchford et al. (2012) have shown that TAs spend more time working with students with higher levels of SEND it is the most vulnerable students who stand to gain the most from TAs becoming more autonomy- 
supportive. This point is pertinent given that research, albeit with mothers as opposed to educators, has demonstrated that low-achieving compared to high-achieving children are particularly likely to benefit from autonomy support ( $\mathrm{Ng}$ et al. 2004). Included within this support for TAs should be information relating to the potential for educators to adopt more controlling styles in response to students' behaviour (for reviews see Finn and Zimmer 2012; Reeve 2009; Skinner et al. 2009). This includes in response to challenging behaviour (Grolnick et al. 1996), a finding of particular significance given that TAs are often deployed to work with individual students with behavioural difficulties (Blatchford et al. 2012). However, a relationship between this form of pressure from below and teachers' and TAs' autonomy-supportive teaching was not found in the present study. Therefore, it is perhaps more important still that support for TAs focuses on an autonomy-supportive approach being beneficial for all (see Guay et al. 2008; Niemiec and Ryan 2009; Reeve, 2009), including students with the most controlled forms of motivation who report benefitting from an autonomy-supportive rather than controlling approach (De Meyer et al. 2015). The emphasis should also be on persuading TAs and other educators of the efficacy of autonomy-supportive teaching given that teachers' beliefs about the effectiveness of particular motivational styles has been shown to be a strong predictor of their adopting such a style (Reeve et al. 2014).

In terms of what this support for TAs might look like, Su and Reeve (2011) demonstrated that interventions to help individuals promote autonomy in others are effective and should therefore be used. Furthermore, as the present study found no relationship between autonomy support and any of the hypothesized antecedents among TAs we would not expect to easily affect TAs' interactional style by addressing these particular social-contextual variables individually. It appears that change has been seen for teachers, for whom the present study suggests that a wide scale vision and policies that promote autonomy support, such as those that have been promoted in the UK, can be effective. Furthermore, McLean (2003) outlines a range of practices that can be adopted by schools to promote feelings of competence among teaching staff which, in line with findings from the present study, would promote autonomy-supportive teaching. In particular, schools should consider whether their chosen methods of performance management engender feelings of competence among staff (for more on performance management in UK schools see Brown 2005; Evans 2011). Importantly, SDT's claim that intentional behaviour is to a large extent a function of individuals' social conditions is universal (Deci and Ryan 1985, 2002, 2012; Ryan and Deci 2000a, 2000b) and therefore we should not expect TAs to represent an exception, rather assume that the social-contextual variables that affect autonomy support among TAs are as yet unknown. As proposed earlier, it is possible that until the TAs' work is characterised by a greater level of structure the impact of other social-contextual variables associated with SDT will be negligible. As training emanating from the DISS 
is now widely available in the UK and focuses to a large extent on helping schools to provide such structure (see "Maximising the impact of teaching assistants" n.d.), it would be worthwhile to reconsider social-contextual variables as predictors of TAs' autonomy support in schools once the effects of this training are apparent.

Secondly, the present study provides further guidance as to how school leaders and educational policymakers can promote greater autonomous motivation among staff which, in turn, will reduce burnout and associated ill-health, absenteeism and high staff turnover (Cherniss 1980; Fernet et al. 2012; Eyal and Roth 2011; Hakanen et al. 2006; Jackson et al. 1986; Soenens et al. 2012). The associations identified in the present study indicate that this can be achieved through measures to reduce the constraints teachers experience at work as well as practices that increase teachers' and TAs' feelings of competence.

Limitations and directions for further research

A number of limitations should be considered when interpreting these findings. The first is the study's reliance solely on self-report data which may have been susceptible to social desirability bias (Barker et al. 2002). Second, the present study does not extend the causal sequence it tests to include student outcomes. Consequently, the impact of variation in autonomy-supportive teaching and its antecedents on student outcomes is based on conjecture, albeit informed by existing research. Third, while SEM permits assertions regarding the plausibility of proposed causal relationships between variables (Byrne 2010) the design is nonetheless correlational and therefore precludes causal inferences from being drawn. Future research should therefore consider experimental procedures (see Furtak and Kunter 2012), or alternatively, a longitudinal design (see Skinner et al. 2008). Fourth, statistical considerations meant significant modifications were made to the original measures. Consequently, the conclusions drawn relate to different operationalisations of a number of the study variables compared to similar research and therefore cross-study comparisons should be made with caution. However, a comparison of the final models using the original and modified versions of the scales indicated that the study's headline finding, that there is a direct positive relationship between teachers' perceived competence for teaching and the autonomy support they offer their students, was maintained. While the models using the original scales generally gave attenuated estimates of associations, in the case of both models with both professional groups the model fit was better for the modified as opposed to the original scales (see Appendix B).

The present study supports the use of SDT as a framework for exploring the impact on student outcomes of teachers and TAs, a group who now represent a quarter of the workforce in UK mainstream schools (Webster 
et al. 2013) and an increasing proportion elsewhere (Giangreco and Doyle 2007; Giangreco et al. 2010). It also demonstrates the need for future educational research with teachers and TAs to consider the importance of their perceptions regarding their own competence. Given that a number of its findings were unexpected, the present study indicates that more research is needed to elucidate the relationship between social-contextual variables, educators' behaviour and, ultimately, student outcomes. For TAs, among whom the models tested in this study accounted for only a very small amount of variance in their autonomy-supportive teaching, we have argued that such research should focus on their experience of structure in the workplace. For teachers, this research should build on recent discoveries indicating that a more nuanced understanding of the variables associated with students' autonomous motivation for learning is required. For example, this could include exploring the differential impact on student outcomes of autonomy-supportive as opposed to psychologically controlling teaching given the two, rather than representing opposite ends of the same continuum, have been shown to have distinct antecedents (Stebbings et al. 2012).

\section{References}

About the theory. (n.d.). Retrieved March 31, 2014, from http://www.selfdeterminationtheory.org/theory

Arbuckle, J.L., \& Wothke, W. (1999). Amos 4.1 user's guide. Chicago: Marketing Department, SPSS Inc., SmallWaters Corporation.

Barker, C., Pistrang, N., \& Elliott, R. (2002). Research methods in clinical psychology: An introduction for students and practitioners (2nd ed.). Chichester: Wiley.

Bartholomew, K. J., Ntoumanis, N., Ryan, R. M., Bosch, J. A., \& Thøgersen-Ntoumani, C. (2011). Selfdetermination theory and diminished functioning: the role of interpersonal control and psychological need thwarting. Personality and Social Psychology Bulletin, 0146167211413125. doi: $10.1177 / 0146167211413125$

Berliner, D. C. (1987). Simple views of effective teaching and a simple theory of classroom instruction. In D. C. Berliner \& B. Rosenshine (Eds.), Talks to teachers (pp. 93-110). New York: Random House.

Blatchford, P., Bassett, P., Brown, P., Martin, C., Russell, A., \& Webster, R. (2009). Deployment and impact of support staff project. Retrieved from http://www.ioe.ac.uk/diss_research_summary.pdf 
Blatchford, P., Bassett, P., Brown, P., Martin, C., Russell, A., \& Webster, R. (2011). The impact of support staff on pupils' 'positive approaches to learning' and their academic progress. British Educational Research Journal, 37(3), 443-464. doi:10.1080/01411921003734645

Blatchford, P., Russell, A., \& Webster, R. (2012). Reassessing the impact of teaching assistants: How research challenges practice and policy. Abingdon, Oxon, UK: Routledge.

Brown, A. (2005). Implementing performance management in England's primary schools. International Journal of Productivity and Performance Management, 54(5/6), 468-481. doi:10.1108/17410400510604593

Brown, T. A. (2006). Confirmatory factor analysis for applied research. New York: Guilford Press.

Browne, M.W. (2001). An overview of analytic rotation in exploratory factor analysis. Multivariate Behavioral Research, 36, 111-150. doi:10.1207/S15327906MBR3601_5

Byrne, B. M. (1994). Burnout: Testing for the validity, replication, and invariance of causal structure across elementary, intermediate, and secondary teachers. American Educational Research Journal, 31, 645-673. doi:10.3102/00028312031003645

Byrne, B. M. (2010). Structural equation modeling with AMOS: Basic concepts, applications and programming. Hove, East Sussex: Routledge.

Cherniss, C. (1980). Professional burnout in human service organizations. New York: Praeger.

Cohen, J. (1988). Statistical power analysis for the behavioral sciences (2nd ed.). Hillside, New Jersey: Lawrence Erlbaum Associates.

De Meyer, J., Soenens, B., Aelterman, N., De Bourdeaudhuij, I., \& Haerens, L. (2015). The different faces of controlling teaching: implications of a distinction between externally and internally controlling teaching for students' motivation in physical education. Physical Education and Sport Pedagogy, 1-21. doi:10.1080/17408989.2015.1112777

Deci, E. L., Koestner, R., \& Ryan, R. M. (1999). A meta-analytic review of experiments examining the effects of extrinsic rewards on intrinsic motivation. Psychological bulletin, 125(6), 627. doi:10.1037/00332909.125.6.627

Deci, E. L., \& Moller, A. C. (2005). The concept of competence: A starting place for understanding intrinsic motivation and self-determined extrinsic motivation. In A. Elliot \& C. Dweck (Eds.), Handbook of competence and motivation. (pp. 579-597). New York: Guilford Press.

Deci, E. L., \& Ryan, R. M. (1985). Intrinsic motivation and self-determination in human behavior. New York: Plenum Publishing Co. 
Deci, E. L., \& Ryan, R. M. (2000). The 'what' and 'why' of goal pursuits: Human needs and the self-determination of behavior. Psychological Inquiry, 11, 227-268. doi:10.1207/S15327965PLI1104_01

Deci, E. L., \& Ryan, R. M. (2002). Handbook of self-determination research. Rochester, NY: University of Rochester Press.

Deci, E. L., \& Ryan, R. M. (2012). Motivation, personality, and development within embedded social contexts: An overview of self-determination theory. In R. M. Ryan (Ed.), The Oxford handbook of human motivation (pp. 85-107). New York; Oxford: Oxford University Press.

Department for Children, Schools and Families (DCSF). (2008). Personalised learning - a practical guide. Retrieved May 22, 2016, from Retrieved May 22, 2016, from

Department for Education and Skills (DfES). (2006). 2020 vision: report of the teaching and learning in 2020 $\begin{array}{lllll}\text { review } & \text { group. } & \text { Retrieved } & \text { May } & \text { 2016, }\end{array}$ http://webarchive.nationalarchives.gov.uk/20130401151715/http:/education.gov.uk/publications/eorderi ngdownload/6856-dfes-teaching\%20and\%20learning.pdf

Evans, L. (2011). The 'shape' of teacher professionalism in England: Professional standards, performance management, professional development and the changes proposed in the 2010 White Paper. British Educational Research Journal, 37(5), 851-870. doi:10.1080/01411926.2011.607231

Eyal, O., \& Roth, G. (2011). Principals' leadership and teachers' motivation: Self-determination theory analysis. Journal of Educational Administration, 49(3), 256-275. doi:10.1108/09578231111129055

Fernet, C., Guay, F., Senécal, C., \& Austin, S. (2012). Predicting intraindividual changes in teacher burnout: The role of perceived school environment and motivational factors. Teaching and Teacher Education, 28(4), 514-525. doi:10.1016/j.tate.2011.11.013

Finn, J. D., \& Zimmer, K. S. (2012). Student engagement: What is it? Why does it matter? In S. L Christeneson, A. L. Reschly \& C. Wylie (Eds.), Handbook of research on student engagement (pp. 97-131). New York: Springer Science \& Business Media.

Friedman, I. A. (1995). Student behavior patterns contributing to teacher burnout. Journal of Educational Research, 88, 281-289. doi:10.1080/00220671.1995.9941312

Furtak, E. M., \& Kunter, M. (2012). Effects of autonomy supportive science teaching on student learning and motivation. Journal of Experimental Education, 80(3), 284-316. doi:10.1080/00220973.2011.573019

Giangreco, M., \& Doyle, M. (2007). Teacher assistants in inclusive schools. In L. Florian (Ed.), The Sage handbook of special education. London: Sage. 
Giangreco, M., Suter, J., \& Doyle, M. (2010). Paraprofessionals in inclusive schools: A review of recent research. Journal of Educational and Psychological Consultation, 20, 41-57. doi:10.1080/10474410903535356

Goudas, M., Biddle, S., \& Underwood, M. (1995). A prospective study of the relationships between motivational orientations and perceived competence with intrinsic motivation and achievement in a teacher education course. Educational psychology, 15(1), 89-96. doi:10.1080/0144341950150108

Grolnick, W. S., Weiss, L., McKenzie, L., \& Wrightman, J. (1996). Contextual, cognitive, and adolescent factors associated with parenting in adolescence. Journal of Youth and Adolescence, 25(1), 33-54.

Guay, F., Boggiano, A. K., \& Vallerand, R. J. (2001). Autonomy support, intrinsic motivation, and perceived competence: Conceptual and empirical linkages. Personality and Social Psychology Bulletin, 27, 643650. doi:10.1177/0146167201276001

Guay, F., Ratelle, C. F., \& Chanal, J. (2008). Optimal learning in optimal contexts: The role of self-determination. Canadian Psychology, 49(3), 233-240. doi:10.1037/a0012758

Hakanen, J. J., Bakker, A. B., \& Schaufeli, W. B. (2006). Burnout and work engagement among teachers. Journal of School Psychology, 43, 495-513. doi:10.1016/j.jsp.2005.11.001

Hooper, D., Coughlan, J., \& Mullen, M.R. (2008). Structural equation modelling: Guidelines for determining model fit. Journal of Business Research Methods, 6, 53-60.

Hu, L., \& Bentler, P. M. (1999). Cutoff criteria for fit indexes in covariance structure analysis: Conventional criteria versus new alternatives. Structural Equation Modeling, 6, 1-55. doi:10.1080/10705519909540118

Jackson, S. E., Schwab, R. L., \& Schuler, R. S. (1986). Toward an understanding of the burnout phenomenon. Journal of Applied Psychology, 71, 630-640. doi:10.1037/0021-9010.71.4.630

Jang, H., Reeve, J., Ryan, R. M., \& Kim, A. (2009). Can self-determination theory explain what underlies the productive, satisfying learning experiences of collectivistically oriented Korean students?. Journal of Educational Psychology, 101(3), 644. doi:10.1037/a0014241

Jang, H., Kim, E. J., \& Reeve, J. (2012). Longitudinal test of self-determination theory's motivation mediation model in a naturally occurring classroom context. Journal of Educational Psychology, 104(4), 1175-1188. doi:10.1037/a0028089

Joreskog, K. G. (1993). Testing structural equation models. In K. A. Bollen \& J. S. Long (Eds.), Testing structural equation models (pp. 294-316). Newbury Park, CA: Sage. 
Kalaja, S., Jaakkola, T., Watt, A., Liukkonen, J., \& Ommundsen, Y. (2009). The associations between seventh grade Finnish students' motivational climate, perceived competence, self-determined motivation, and fundamental movement skills. European Physical education review, 15(3), 315-335. doi:10.1177/1356336X09364714

Kline, R. B. (2011). Principles and practice of structural equation modeling. New York: Guilford.

Leroy, N., Bressoux, P., Sarrazin, P. H., \& Trouilloud, D., (2007). Impact of teachers' implicit theories and perceived pressures on the establishment of an autonomy supportive climate. European Journal of Psychology of Education, 22(4), 529-545.

MacCallum, R. C., Browne, M. W., \& Sugawara, H. M. (1996). Power analysis and determination of sample size for covariance structure modeling. Psychological Methods, 1, 130-149. doi:10.1037/1082-989X.1.2.130

Maslach, C., Schaufeli, W., \& Leiter, M. (2001). Job burnout. Annual Review of Psychology, 52, 397-422. doi:10.1146/annurev.psych.52.1.397

Maximising the impact of teaching assistants. (n.d.). Retrieved May 22, 2016, from http://maximisingtas.co.uk/

McLean, A. (2003). The motivated school. London: Sage.

Fei-Yin Ng, F., Kenney-Benson, G. A., \& Pomerantz, E. M. (2004). Children's achievement moderates the effects of mothers' use of control and autonomy support. Child Development, 75(3), 764-780. doi:10.1111/j.1467-8624.2004.00705.x

Niemiec, C., \& Ryan, R. M. (2009). Autonomy, competence, and relatedness in the classroom: Applying selfdetermination theory to educational practice. Theory and Research in Education, 7(2), 133-144. doi:10.1177/1477878509104318

Patrick, B. C., Skinner, E. A., \& Connell, J. P. (1993). What motivates children's behavior and emotion? Joint effects of perceived control and autonomy in the academic domain. Journal of Personality and Social Psychology, 65, 781-791. doi:10.1037/0022-3514.65.4.781

Pelletier, L. G., \& Vallerand, R. J. (1996). Supervisors' beliefs and subordinates' intrinsic motivation: A behavioral confirmation analysis. Journal of Personality \& Social Psychology, 71, 331-340. doi:10.1037/00223514.7.2.331

Pelletier, L. G., Levesque, C. S., \& Legault L. (2002). Pressure from above and pressure from below as determinants of teachers' motivation and teaching behavior. Journal of Educational Psychology, 94, 186196. doi:10.1037/0022-0663.94.1.186 
Perceived Competence Scales. (n.d.). Retrieved March 31, 2014, from http://selfdeterminationtheory.org/questionnaires/10-questionnaires/49

Radel, R., Pelletier, L., \& Sarrazin, P. (2013). Restoration processes after need thwarting: When autonomy depends on competence. Motivation and Emotion, 37(2), 234-244. doi:10.1007/s11031-012-9308-3

Radford, J., Blatchford, P., \& Webster, R. (2011). Opening up and closing down: How teachers and TAs manage turn-taking, topic and repair in mathematics lessons. Learning and Instruction, 21(5), 625-635. doi:10.1016/j.learninstruc.2011.01.004

Reeve, J. (2009). Why teachers adopt a controlling motivating style toward students and how they can become more autonomy supportive. Educational Psychologist, 44, 159-175. doi:10.1080/00461520903028990

Reeve, J., \& Jang, H. (2006). What teachers say and do to support students' autonomy during a learning activity. Journal of educational psychology, 98(1), 209. doi:10.1037/0022-0663.98.1.209

Reeve, J., Vansteenkiste, M., Assor, A., Ahmad, I., Cheon, S. H., Jang, H., ... \& Wang, C. J. (2014). The beliefs that underlie autonomy-supportive and controlling teaching: A multinational investigation. Motivation and Emotion, 38(1), 93-110. doi:10.1007/s11031-013-9367-0

Rocchi, M. A., Pelletier, L. G., \& Couture, A. L. (2013). Determinants of coach motivation and autonomy supportive coaching behaviours. Psychology of Sport and Exercise, 14(6), 852-859. doi:10.1016/j.psychsport.2013.07.002

Roth, G., Assor, A., Kanat-Maymon, Y., \& Kaplan, H. (2007). Autonomous motivation for teaching: How selfdetermined teaching may lead to self-determined learning. Journal of Educational Psychology, 99, 761774. doi:10.1037/0022-0663.99.4.761

Ryan, R. M., \& Connell, J. P. (1989). Perceived locus of causality and internalization: Examining reasons for acting in two domains. Journal of Personality and Social Psychology, 57, 749-761. doi:10.1037/00223514.57.5.749

Ryan, R. M., \& Deci, E. L. (2000a). Self-determination theory and the facilitation of intrinsic motivation, social development, and well-being. American Psychologist, 55, 68-78. doi:10.1037/0003-066X.55.1.68

Ryan, R. M., \& Deci, E. L. (2000b). Intrinsic and extrinsic motivations: Classic definitions and new directions. Contemporary Educational Psychology, 25, 54-67. doi:10.1006/ceps.1999.1020

Ryan, R. M., \& Deci, E. L. (2003). On assimilating identities to the self: A self-determination theory perspective on internalization and integrity within cultures. In M. R. Leary \& J. P. Tangey (Eds.), Handbook of self and identity (pp. 255-273). New York: Guilford. 
Sharples, J., Webster, R., \& Blatchford, P. (2015). Making best use of teaching assistants: guidance report. Education Endowment Foundation. Retrieved May 22, 2016, from, https://v1.educationendowmentfoundation.org.uk/uploads/pdf/Making_best_use_of_TAs_printable.pdf

Sierens, E., Vansteenkiste, M., Goossens, L., Soenens, B., \& Dochy, F. (2009). The synergistic relationship of perceived autonomy-support and structure in the prediction of self-regulated learning. British Journal of Educational Psychology, 79, 57e68. doi:10.1348/000709908X304398

Skinner, E. A., \& Belmont, M. J. (1993). Motivation in the classroom: Reciprocal effects of teacher behavior and student engagement across the school year. Journal of Educational Psychology, 85, 571-581. doi:10.1037/0022-0663.85.4.571

Skinner, E., Furrer, C., Marchand, G., \& Kindermann, T. (2008). Engagement and disaffection in the classroom: Part of a larger motivational dynamic? Journal of Educational Psychology, 100(4), 765-781. doi:10.1037/a0012840

Skinner, E. A., Kindermann, T. A., Connell, J. P., \& Wellborn, J. G. (2009). Engagement and disaffection as organizational constructs in the dynamics of motivational development. In K. Wentzel, A. Wigfield \& D. Miele (Eds.), Handbook of motivation at school. (pp. 223-245). London: Routledge.

Soenens, B., Sierens, E., Vansteenkiste, M., Dochy, F., \& Goossens, L. (2012). Psychologically controlling teaching: Examining outcomes, antecedents, and mediators. Journal of Educational Psychology, 104(1), 108-120. doi:10.1037/a0025742

Standage, M., Duda, J. L., \& Ntoumanis, N. (2003). A model of contextual motivation in physical education: Using constructs from self-determination and achievement goal theories to predict physical activity intentions. Journal of educational psychology, 95(1), 97. doi:10.1037/0022-0663.95.1.97

Stebbings, J., Taylor, I. M., Spray, C. M., \& Ntoumanis, N. (2012). Antecedents of perceived coach interpersonal behaviors: The coaching environment and coach psychological well-and ill-being. Journal of Sport \& Exercise Psychology, 34(4), 481-502.

Su, Y., \& Reeve, J. (2011). A meta-analysis of the effectiveness of intervention programs designed to support autonomy. Educational Psychology Review, 23, 159-188. doi:10.1007/s10648-010-9142-7

Tabachnick, B.G., \& Fidell, L.S. (2007). Using Multivariate Statistics (5th ed.). New York: Allyn and Bacon.

Vallerand, R. J., Fortier, M. S., \& Guay, F. (1997). Self-determination and persistence in a real-life setting: toward a motivational model of high school dropout. Journal of Personality and Social Psychology, 72(5), 1161. doi:10.1037/0022-3514.72.5.1161 
Vansteenkiste, M., Sierens, E., Goossens, L., Soenens, B., Dochy, F., Mouratidis, A., ... \& Beyers, W. (2012). Identifying configurations of perceived teacher autonomy support and structure: Associations with selfregulated learning, motivation and problem behavior. Learning and Instruction, 22(6), 431-439.

Vansteenkiste, M., \& Ryan, R. M. (2013). On psychological growth and vulnerability: Basic psychological need satisfaction and need frustration as a unifying principle. Journal of Psychotherapy Integration, 23(3), 263. doi:10.1037/a0032359

Webster, R., Blatchford, P., Bassett, P., Brown, P., Martin, C., \& Russell, A. (2011). The wider pedagogical role of teaching assistants. School Leadership and Management, 31(1), 3-20. doi:10.1080/13632434.2010.540562

Webster, R., Blatchford, P., \& Russell, A. (2013). Challenging and changing how schools use teaching assistants: Findings from the Effective Deployment of Teaching Assistants project. School Leadership and Management, 33(1), 78-96. doi:10.1080/13632434.2012.724672

Wellborn J., Connell, J., Skinner, E., \& Pierson, L. (1992). Teacher as social context (TASC). Two measures of teacher provision of involvement, structure, and autonomy support. Technical Report. Rochester, New York: University of Rochester. 
Table 1 Definitions and instructional behaviours associated with controlling and autonomy support (reproduced from Reeve, 2009, p. 160)

\begin{tabular}{|c|c|}
\hline Controlling & Autonomy Support \\
\hline Definition & Definition \\
\hline Interpersonal sentiment and behaviour teachers & Interpersonal sentiment and behaviour \\
\hline provide during instruction to pressure students & teachers provide during instruction to \\
\hline \multirow[t]{2}{*}{ to think, feel, or behave in a specific way. } & identify, nurture, and develop students' inner \\
\hline & motivational resources. \\
\hline Instructional Behaviours & Instructional Behaviours \\
\hline Rely on outer sources of motivation. & Nurture inner motivational resources. \\
\hline Neglect explanatory rationales. & Provide explanatory rationales. \\
\hline Rely on pressure-inducing language. & Rely on non-controlling and informational \\
\hline Display impatience for students to produce the & language. \\
\hline right answer. & Display patience to allow time for self-paced \\
\hline Assert power to overcome students' & learning. \\
\hline complaints/expressions of negative affect. & Acknowledge and accept expressions of \\
\hline & negative affect. \\
\hline
\end{tabular}


Table 2 Bivariate correlations between study variables

\begin{tabular}{|c|c|c|c|c|c|c|c|c|c|}
\hline Variable & 1. & 2. & 3. & 4. & 5. & 6. & 7. & 8. & 9. \\
\hline \multicolumn{10}{|l|}{ Autonomous motivation for teaching } \\
\hline 1. Intrinsic motivation & - & $-.37 * *$ & .11 & $.17 *$ & -.01 & $-.19 * *$ & $.16^{*}$ & -.02 & $.25 * *$ \\
\hline 2. External regulation & $-.21 * *$ & - & -.08 & $-.23 * *$ & $.20 * *$ & $.20 * *$ & $-.16^{*}$ & .11 & $-.17 *$ \\
\hline \multicolumn{10}{|l|}{ Autonomy-supportive teaching } \\
\hline 3. Choice & $.17 *$ & -.03 & - & $-.18 * *$ & $.29 * *$ & -.10 & $.25^{* *}$ & -.00 & $.16^{*}$ \\
\hline 4. Controlling Behaviour & -.01 & -.08 & $-.34 * *$ & - & $-.34 * *$ & -.08 & -.05 & .12 & .01 \\
\hline 5. Respect & .05 & .00 & $.47 * *$ & $-.36 * *$ & - & .05 & .10 & -.06 & .07 \\
\hline \multicolumn{10}{|l|}{ Constraints at work } \\
\hline 6. Constraints at work & $-.32 * *$ & $.16^{*}$ & $-.14^{*}$ & -.04 & -.04 & - & $-.28 * *$ & $.14 *$ & $-.36 * *$ \\
\hline \multicolumn{10}{|c|}{ Perceptions of students' autonomous motivation } \\
\hline \multicolumn{10}{|l|}{ towards school } \\
\hline 7. Intrinsic motivation & $.25^{* *}$ & $-.15^{*}$ & $.19 * *$ & .00 & .08 & $-.29 * *$ & - & $-.62 * *$ & $.16^{*}$ \\
\hline 8. External regulation & -.03 & .11 & -.05 & .02 & -.00 & -.02 & $-.35 * *$ & - & $-.16^{*}$ \\
\hline \multicolumn{10}{|l|}{ Perceived competence for teaching } \\
\hline 9. Perceived competence for teaching & $.23^{* *}$ & .06 & $.14 *$ & $-.15^{*}$ & $.19 * *$ & $-.26 * *$ & .07 & -.04 & - \\
\hline
\end{tabular}

Values for teachers are below the diagonal line; values for TAs are above the diagonal line.

$* p<.05 ; * * p<.01$ 
Table 3 Means, standard deviations, and role differences for study variables

\begin{tabular}{|c|c|c|c|c|c|c|c|}
\hline \multirow[t]{2}{*}{ Variable } & \multicolumn{2}{|c|}{ Total } & \multicolumn{2}{|c|}{ Teachers } & \multicolumn{2}{|c|}{ Teaching assistants } & \multirow{2}{*}{$\begin{array}{c}\text { Significance test, } \\
\text { role differences } \\
t \text { Test }(d f)\end{array}$} \\
\hline & $M$ & $S D$ & $M$ & $S D$ & $M$ & $S D$ & \\
\hline Autonomous motivation for teaching & 17.74 & 10.52 & 15.32 & 9.52 & 20.00 & 10.93 & $t(400)=-4.53, p<.001, d=.46$ \\
\hline Intrinsic motivation & 51.72 & 6.78 & 50.69 & 6.60 & 52.66 & 6.82 & $t(400)=-2.93, p<.01, d=.29$ \\
\hline External regulation & -33.98 & 10.14 & -35.37 & 8.36 & -32.69 & 11.41 & $t(400)=-2.70, p<.01, d=.27$ \\
\hline Autonomy-supportive teaching & 8.20 & 1.41 & 8.58 & 1.34 & 7.86 & 1.38 & $t(400)=5.32, p<.001, d=.53$ \\
\hline Choice & 2.84 & .62 & 2.98 & .57 & 2.71 & .63 & $t(400)=4.53, p<.001, d=.45$ \\
\hline Controlling behaviour ${ }^{\mathrm{a}}$ & 2.42 & .67 & 2.59 & .64 & 2.26 & .65 & $t(400)=5.17, p<.001, d=.51$ \\
\hline Respect & 2.95 & .59 & 3.01 & .53 & 2.89 & .63 & $t(400)=1.98, p<.01, d=.21$ \\
\hline Constraints at work & 3.45 & .73 & 3.22 & .61 & 3.66 & .76 & $t(400)=6.47, p<.001, d=.64$ \\
\hline Perception of students' autonomous & 5.93 & 9.85 & 6.50 & 11.18 & 5.40 & 8.43 & $t(400)=1.12, p=.26, d=.11$ \\
\hline \multicolumn{8}{|l|}{ motivation towards school } \\
\hline Intrinsic motivation & 32.37 & 9.03 & 35.23 & 8.44 & 29.73 & 8.77 & $t(400)=6.41, p<.001, d=.64$ \\
\hline External regulation & -26.44 & 10.82 & -28.73 & 10.90 & -24.32 & 10.34 & $t(400)=-4.17, p<.001, d=.42$ \\
\hline Perceived competence for teaching & 5.81 & .80 & 5.70 & .76 & 5.90 & .83 & $t(400)=-2.54, p<.05, d=.25$ \\
\hline
\end{tabular}

${ }^{\text {a }}$ Scores have been reversed so that higher scores indicate less controlling behaviour. 
Table 4 Results of chi-square difference (invariance) tests comparing key SEM parameters between TAs and teachers

\begin{tabular}{|c|c|c|c|c|c|c|}
\hline \multirow{3}{*}{ Model parameters } & \multirow{2}{*}{\multicolumn{3}{|c|}{$\begin{array}{c}\text { Model } 1 . \text { Fully mediated } \\
\text { model }\end{array}$}} & \multicolumn{3}{|c|}{ Model 2. Partially mediated } \\
\hline & & & & & model & \\
\hline & $d f$ & $\chi^{2}$ & $p$ & $d f$ & $\chi^{2}$ & $p$ \\
\hline $\mathrm{CAW} \rightarrow \mathrm{AMT}$ & 1 & 5.222 & $.022 *$ & 1 & 4.890 & $.027 *$ \\
\hline $\mathrm{PCT} \rightarrow \mathrm{AMT}$ & 1 & 0.825 & .364 & 1 & 0.351 & .554 \\
\hline $\mathrm{PSM} \rightarrow \mathrm{AMT}$ & 1 & 1.561 & .212 & 1 & 1.391 & .238 \\
\hline $\mathrm{AMT} \rightarrow \mathrm{AST}$ & 1 & 3.031 & .082 & 1 & 0.003 & .957 \\
\hline $\mathrm{CAW} \leftrightarrow \mathrm{PCT}$ & 1 & 2.271 & .132 & 1 & 2.121 & .145 \\
\hline $\mathrm{CAW} \leftrightarrow \mathrm{PSM}$ & 1 & 2.364 & .124 & 1 & 2.352 & .125 \\
\hline $\mathrm{PSM} \leftrightarrow \mathrm{PCT}$ & 1 & 1.708 & .191 & 1 & 1.712 & .191 \\
\hline $\mathrm{CAW} \rightarrow \mathrm{AST}$ & & & & 1 & 0.663 & .416 \\
\hline $\mathrm{PCT} \rightarrow \mathrm{AST}$ & & & & 1 & 3.733 & .053 \\
\hline $\mathrm{PSM} \rightarrow \mathrm{AST}$ & & & & 1 & 0.020 & .889 \\
\hline
\end{tabular}

CAW = constraints at work PSM = perception of students' motivation towards school; PCT = perceived competence for teaching; AMT = autonomous motivation for teaching; $\mathrm{AST}=$ autonomy-supportive teaching. $\rightarrow=$ regression path; $\leftrightarrow=$ correlation

$* p<.05$ 

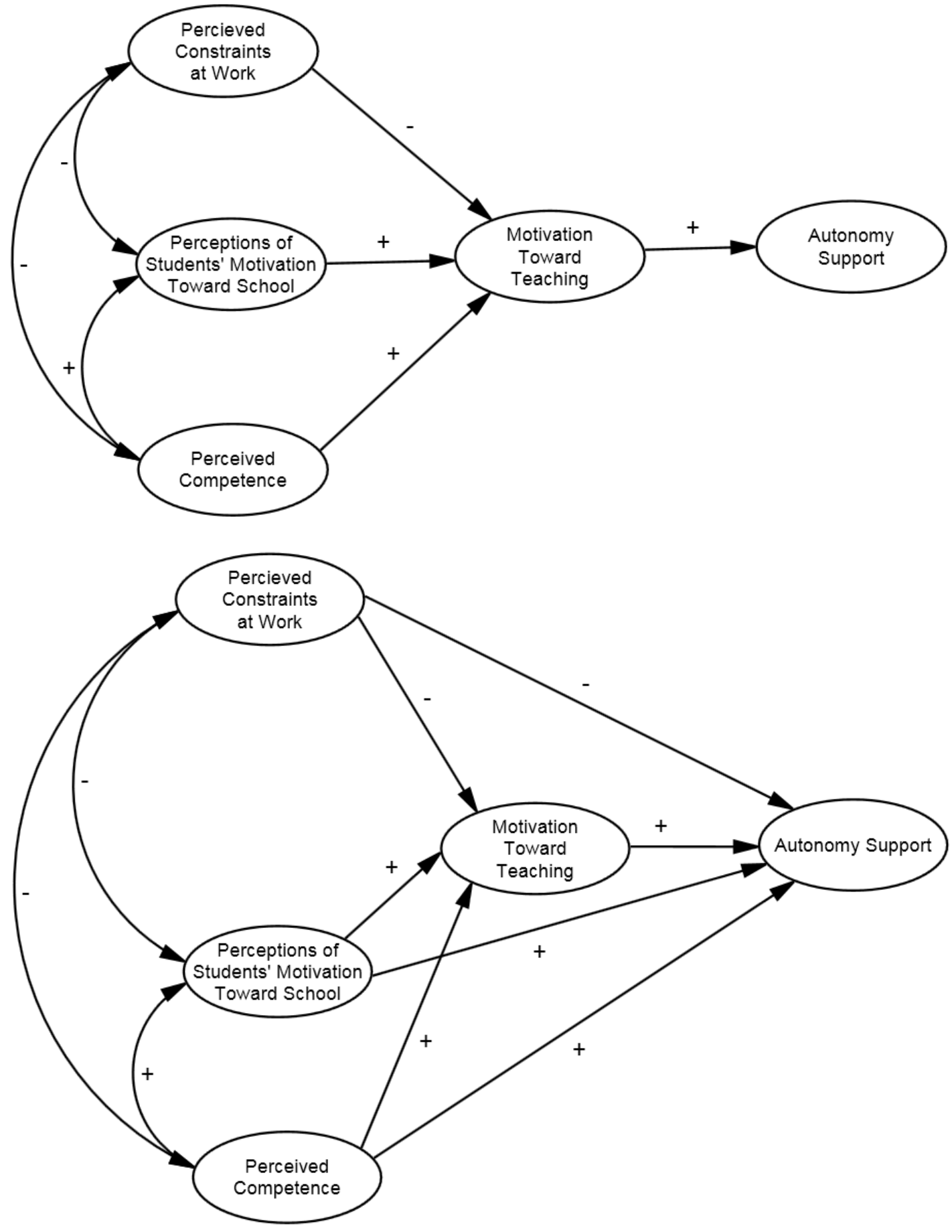

Fig 1. This figure was created in Amos (Version 21, Arbuckle and Wothke 1999).

Arbuckle, J.L., \& Wothke, W. (1999). Amos 4.1 user's guide. Chicago: Marketing Department, SPSS Inc., SmallWaters Corporation. 


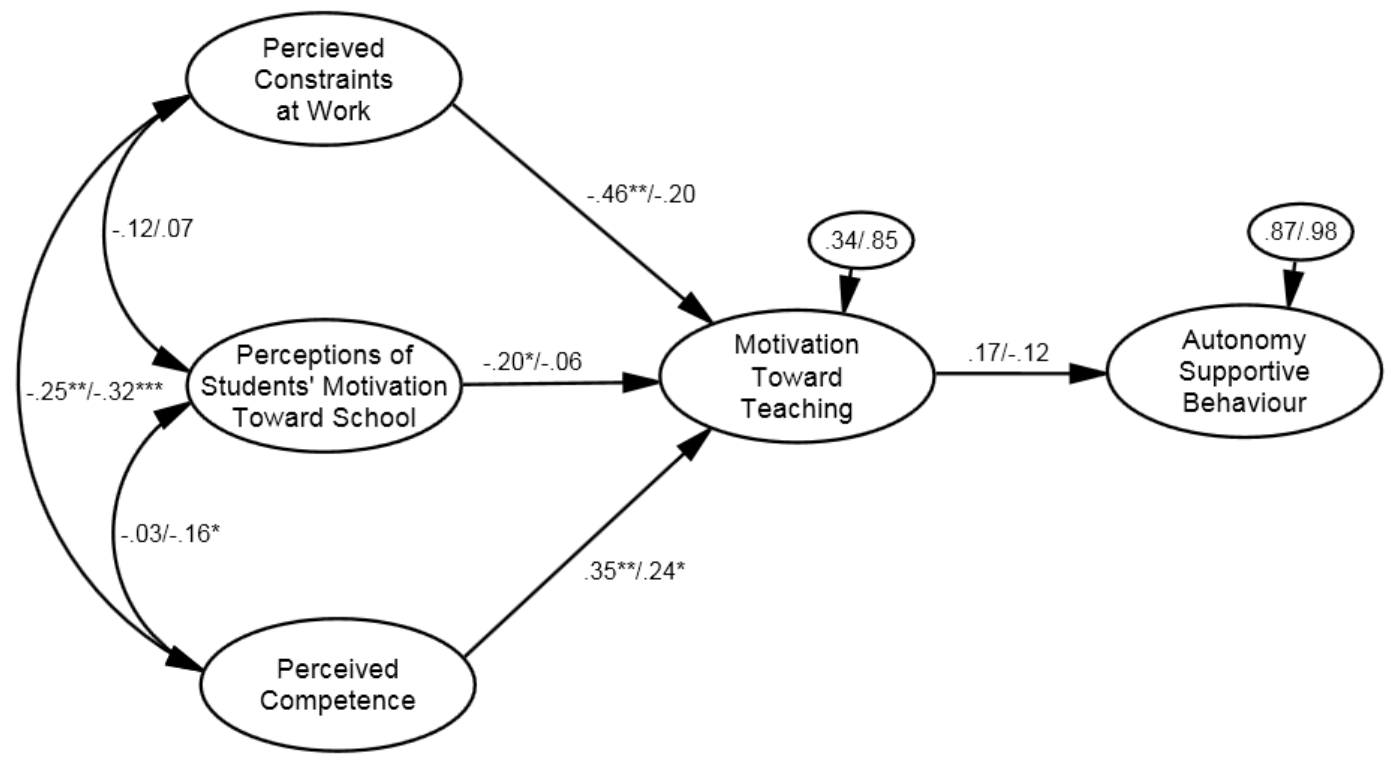

Fig 2. This figure was created in Amos (Version 21, Arbuckle and Wothke 1999).

Arbuckle, J.L., \& Wothke, W. (1999). Amos 4.1 user's guide. Chicago: Marketing Department, SPSS Inc., SmallWaters Corporation. 


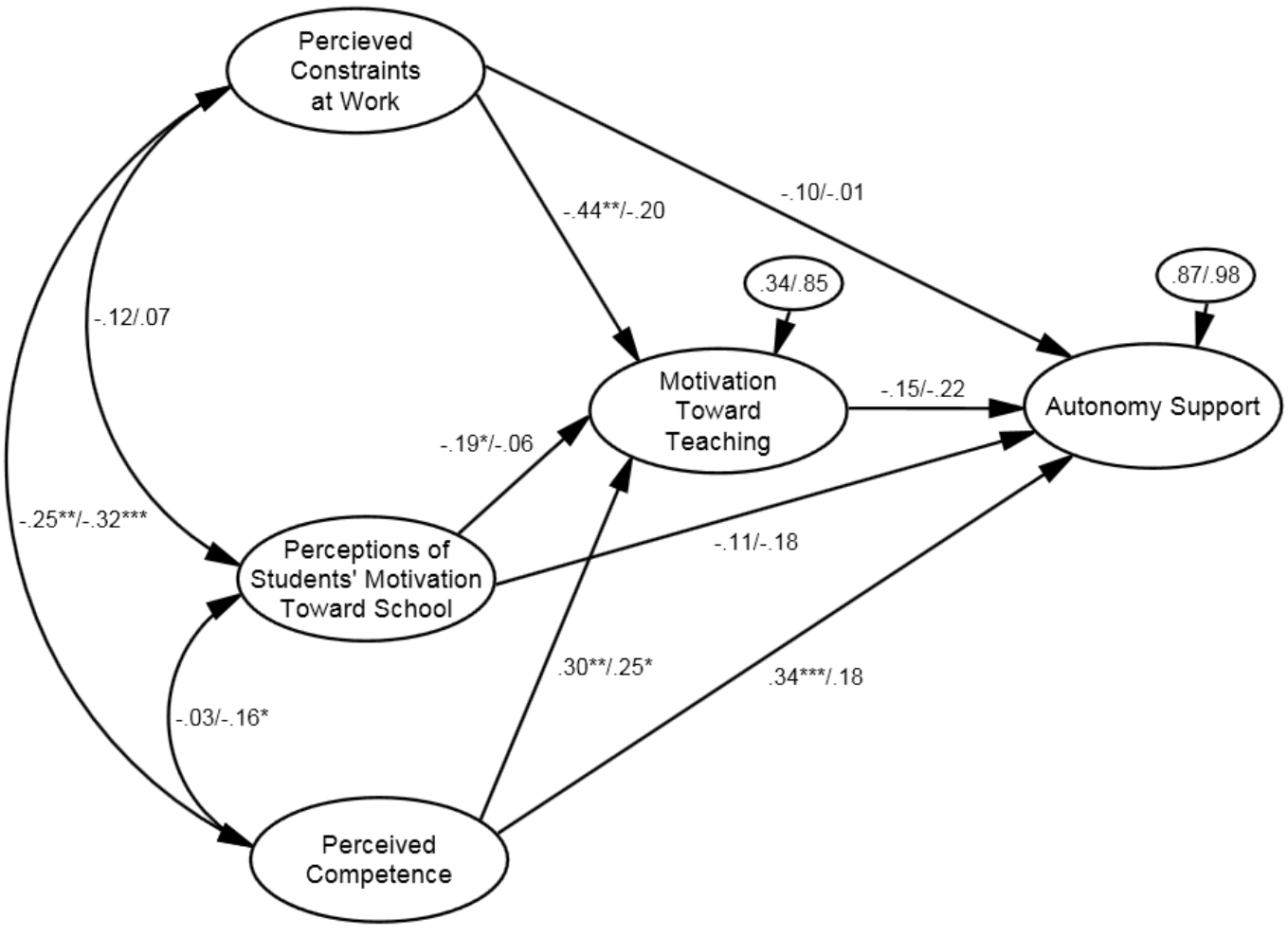

Fig 3. This figure was created in Amos (Version 21, Arbuckle and Wothke 1999).

Arbuckle, J.L., \& Wothke, W. (1999). Amos 4.1 user's guide. Chicago: Marketing Department, SPSS Inc., SmallWaters Corporation. 
Appendix A Principal components analyses (PCA)

Table 5 Autonomous Motivation for Teaching (AMTS) Scale: factor loadings for the original scale

\begin{tabular}{|c|c|c|c|c|}
\hline & \multicolumn{4}{|c|}{ Component } \\
\hline & 1 & 2 & 3 & 4 \\
\hline Item 1. External regulation & .798 & & & \\
\hline Item 2. Introjected regulation & .750 & & & \\
\hline Item 3. Identified regulation & .563 & & & \\
\hline Item 4. Intrinsic motivation & & .447 & & \\
\hline Item 5. Introjected regulation & & & & .513 \\
\hline Item 6. Intrinsic motivation & & & & .793 \\
\hline Item 7 . Identified regulation & & & & .714 \\
\hline Item 8. External regulation & .641 & & & \\
\hline Item 9. Intrinsic motivation & & .425 & & .454 \\
\hline Item 10 . Identified regulation & & 608 & & \\
\hline Item 11. External regulation & .447 & & & \\
\hline Item 12. Introjected regulation & & & .790 & \\
\hline Item 13. External regulation & & & .573 & \\
\hline Item 14 . Identified regulation & & .737 & & \\
\hline Item 15 . Intrinsic motivation & & .837 & & \\
\hline Item 16. Introjected regulation & & & .779 & \\
\hline
\end{tabular}

To aid interpretation, absolute values below .4 have been suppressed.

Principal components analysis was using oblique rotation. 
Table 6 Autonomous Motivation for Teaching (AMTS) Scale: factor loadings for the final modified scale

\begin{tabular}{lcc}
\hline & \multicolumn{2}{c}{ Component } \\
& 1 & 2 \\
\hline Item 1. External regulation & .561 & .749 \\
Item 4. Intrinsic motivation & .697 & \\
Item 6. Intrinsic motivation & & .803 \\
Item 8. External regulation & .758 & .653 \\
Item 9. Intrinsic motivation & & .501 \\
Item 11. External regulation & & \\
Item 13. External regulation & .737 & \\
Item 15. Intrinsic motivation & & \\
\hline
\end{tabular}

To aid interpretation, absolute values below .4 have been suppressed. Factor solutions were selected on the basis of eigenvalues greater than 1 .

Principal components analysis was using oblique rotation. 
Table 7 Perception of Students Motivation towards School (PSMS) Scale: factor loadings for the original scale

\begin{tabular}{|c|c|c|}
\hline & \multicolumn{2}{|c|}{ Component } \\
\hline & 1 & 2 \\
\hline Item 1. Intrinsic motivation & & .882 \\
\hline Item 2. Identified regulation & .712 & \\
\hline Item 3. External regulation & .820 & \\
\hline Item 4. Introjected regulation & .445 & \\
\hline Item 5. Intrinsic motivation & & 647 \\
\hline Item 6. Identified regulation & .841 & \\
\hline Item 7. External regulation & .901 & \\
\hline Item 8. Introjected regulation & & .675 \\
\hline Item 9. Intrinsic motivation & & .901 \\
\hline Item 10. Identified regulation & .782 & \\
\hline Item 11. External regulation & .863 & \\
\hline Item 12 . Intrinsic motivation & & .628 \\
\hline Item 13. Introjected regulation & .515 & .448 \\
\hline Item 14 . Identified regulation & .892 & \\
\hline Item 15. External regulation & .972 & \\
\hline Item 16. Introjected regulation & .882 & \\
\hline
\end{tabular}

To aid interpretation, absolute values below .4 have been suppressed.

Principal components analysis was using oblique rotation.

Items belonging to the external regulation and intrinsic motivation subscales loaded on separate factors.

However, all identified regulation items loaded with external regulation items which should not have been the case as theoretically these items are closer along the continuum of relative autonomy to those belonging to the intrinsic motivation subscale. Similarly, two of the four introjected regulation items loaded with intrinsic motivation despite reflecting relatively less autonomous motivation meaning they should have loaded with items from the external regulation subscale. The remaining two items from the introjected regulation subscale were those with the lowest factor loadings on the first component. On this basis the entire introjected and identified regulation subscales were removed. 
Table 8 Perception of Students Motivation towards School (PSMS) Scale: factor loadings for the final modified scale

\begin{tabular}{lcc}
\hline & \multicolumn{2}{c}{ Component } \\
& 1 & 2 \\
\hline Item 1. Intrinsic motivation & .810 & .897 \\
Item 3. External regulation & & .689 \\
Item 5. Intrinsic motivation & .883 & \\
Item 7. External regulation & & .894 \\
Item 9. Intrinsic motivation & .870 & \\
Item 11. External regulation & & .631 \\
Item 12. Intrinsic motivation & .944 & \\
Item 15. External regulation & & \\
\hline
\end{tabular}

To aid interpretation, absolute values below .4 have been suppressed. Factor solutions were selected on the basis of eigenvalues greater than 1 .

Principal components analysis was using oblique rotation. 
Table 9 Constraints at Work (CWS) Scale: factor loadings for the final modified scale

\begin{tabular}{lc}
\hline & Component \\
& 1 \\
\hline Item 1. Curriculum & .315 \\
Item 2. School management & .655 \\
Item 3. Colleagues & .003 \\
Item 4. School management & .264 \\
Item 5. Curriculum & .586 \\
Item 6. School management & .531 \\
Item 7. Curriculum & .484 \\
Item 8. Colleagues & .830 \\
Item 9. Colleagues & .782 \\
\hline
\end{tabular}

Items with loadings below .4 were removed.

Principal components analysis was using oblique rotation. 
Appendix B Comparison of mediated and partially mediated models using final modified and original scales

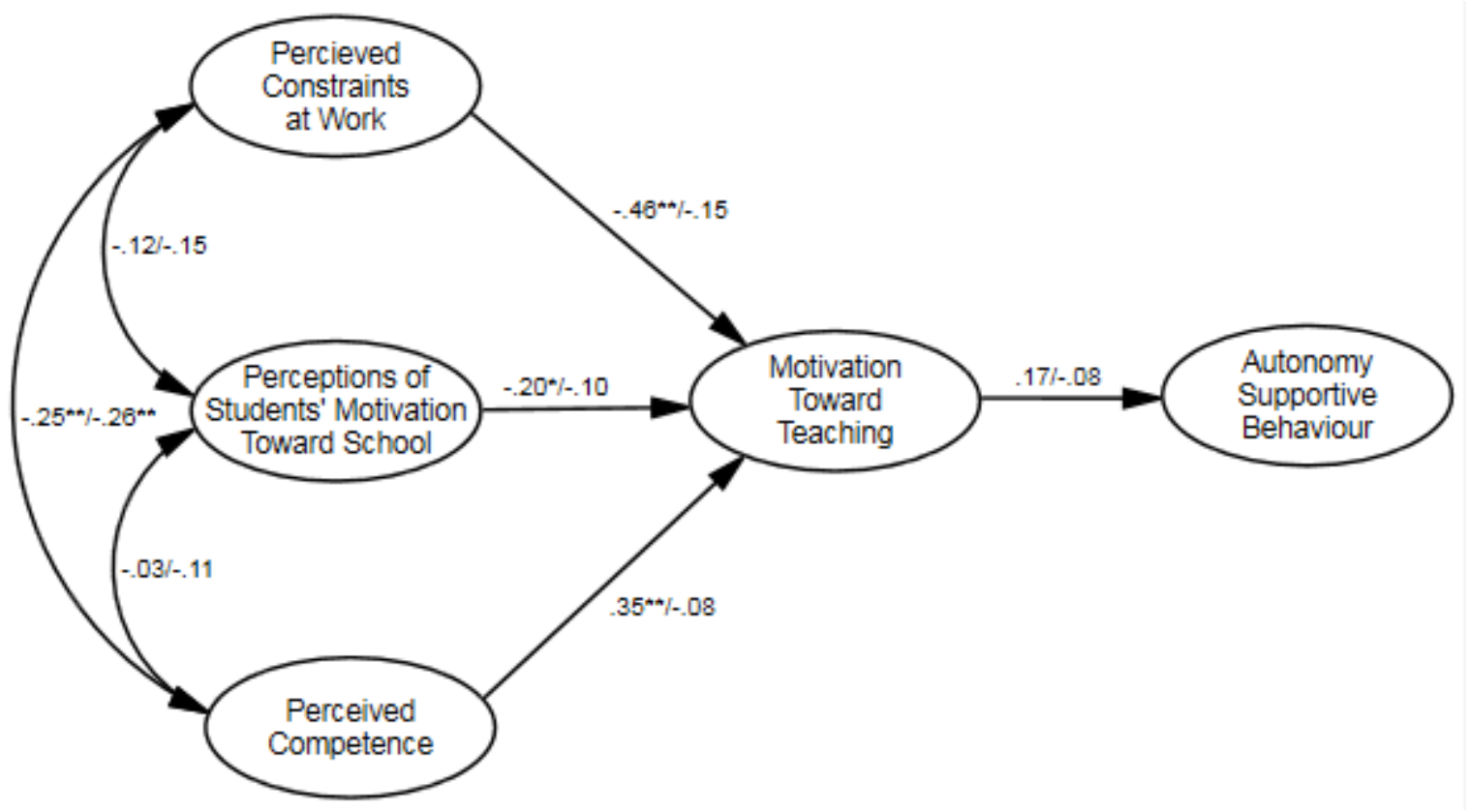

Fig. 4 Comparison of mediated model using final modified and original scales for teachers

$* p<.05 ; * * p<.01 ; * * * p<.001$

Note Standardised coefficients are shown with estimates for final modified scales presented on the left and estimates for original scales presented on the right. Model also controls for gender effects on autonomous motivation for teaching and setting effects on all variables.

Final modified scale fit $=\chi^{2}(562)=865.76, p<.001 ;$ RMSEA $=.05,90 \%$ RMSEA CI $[.05, .06] ;$ CFI $=.87$

Original scale fit $=\chi^{2}(1649)=2518.12, p<.001 ;$ RMSEA $=.05,90 \%$ RMSEA CI $[.05, .06] ;$ CFI $=.81$ 


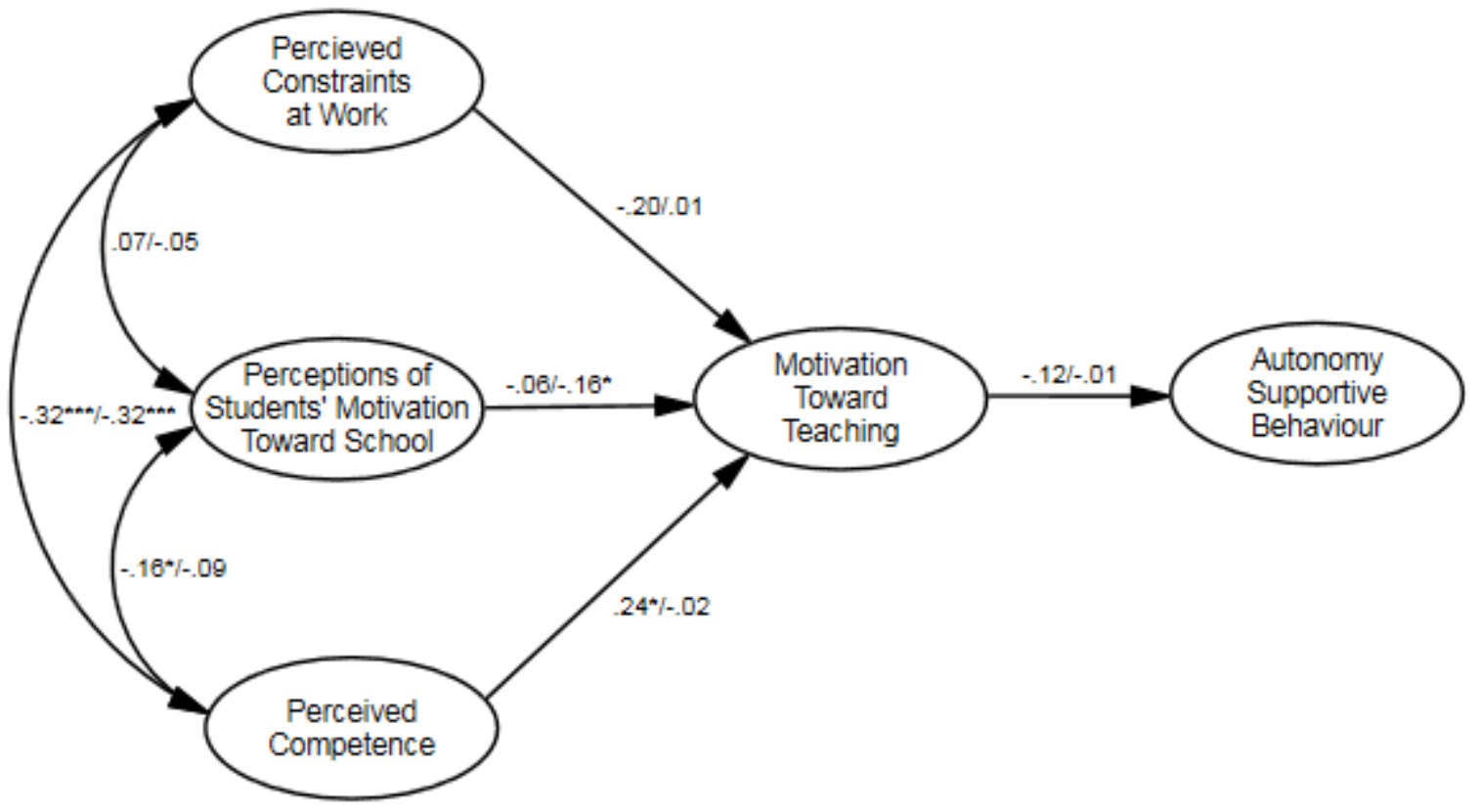

Fig. 5 Comparison of mediated model using final modified and original scales for TAs

$* p<.05 ; * * p<.01 ; * * * p<.001$

Note Standardised coefficients are shown with estimates for final modified scales presented on the left and estimates for original scales presented on the right. Model also controls for gender effects on autonomous motivation for teaching and setting effects on all variables.

Final modified scale fit $=\chi^{2}(562)=847.90, p<.001 ;$ RMSEA $=.05,90 \%$ RMSEA CI $[.04, .06] ;$ CFI $=.91$

Original scale fit $=\chi^{2}(1649)=2521.54, p<.001 ;$ RMSEA $=.05,90 \%$ RMSEA CI $[.05, .05] ;$ CFI $=.86$ 


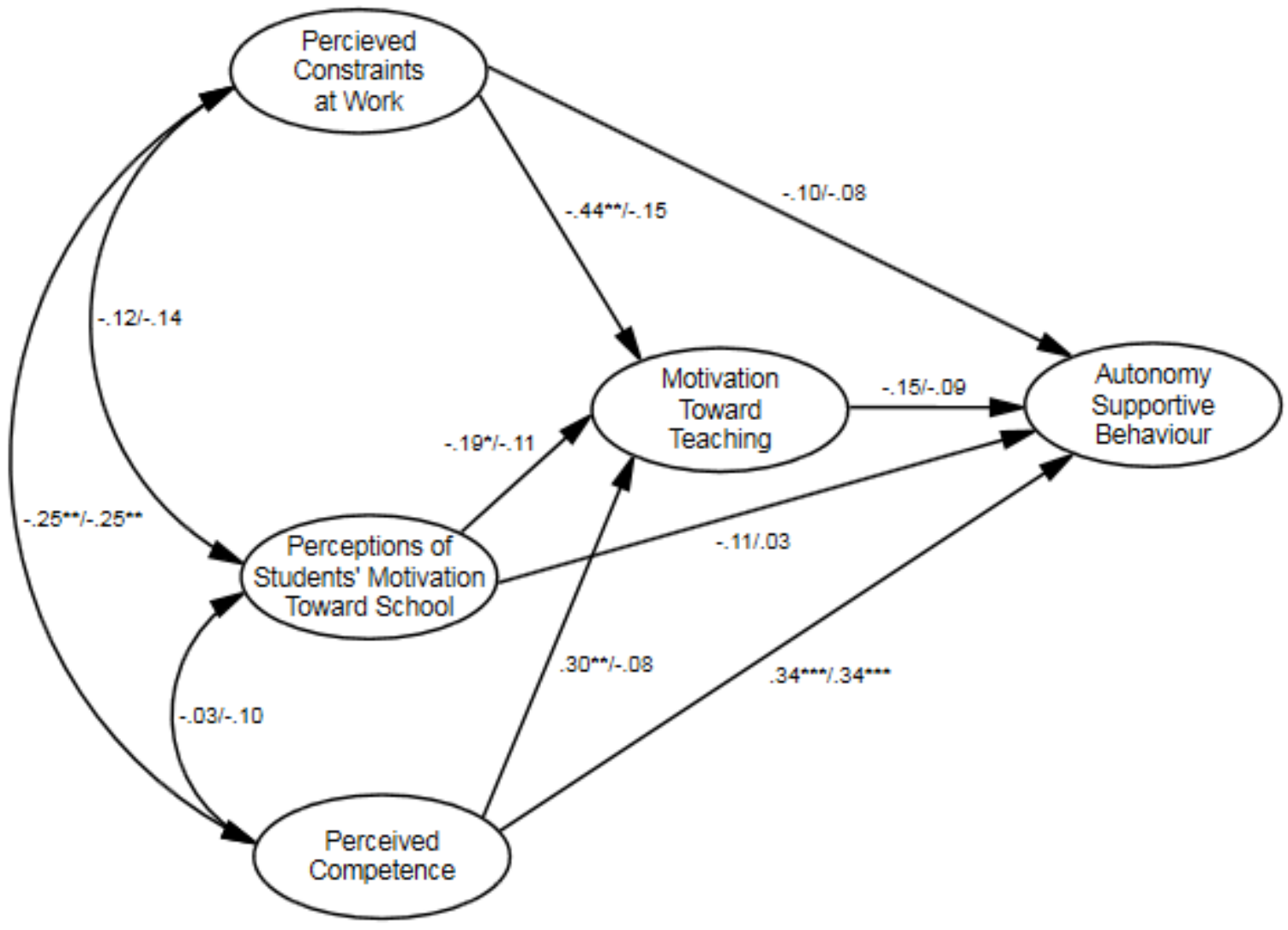

Fig. 6 Comparison of partially mediated model using final modified and original scales for teachers

$* p<.05 ; * * p<.01 ; * * * p<.001$

Note Standardised coefficients are shown with estimates for final modified scales presented on the left and estimates for original scales presented on the right. Model also controls for gender effects on autonomous motivation for teaching and setting effects on all variables.

Final modified scale fit $=\chi^{2}(559)=853.55, p<.001 ;$ RMSEA $=.05,90 \%$ RMSEA CI $[.05, .06] ;$ CFI $=.87$

Original scale fit $=\chi^{2}(1646)=2501.78, p<.001 ; \operatorname{RMSEA}=.05,90 \%$ RMSEA CI $[.05, .06] ; \mathrm{CFI}=.81$ 


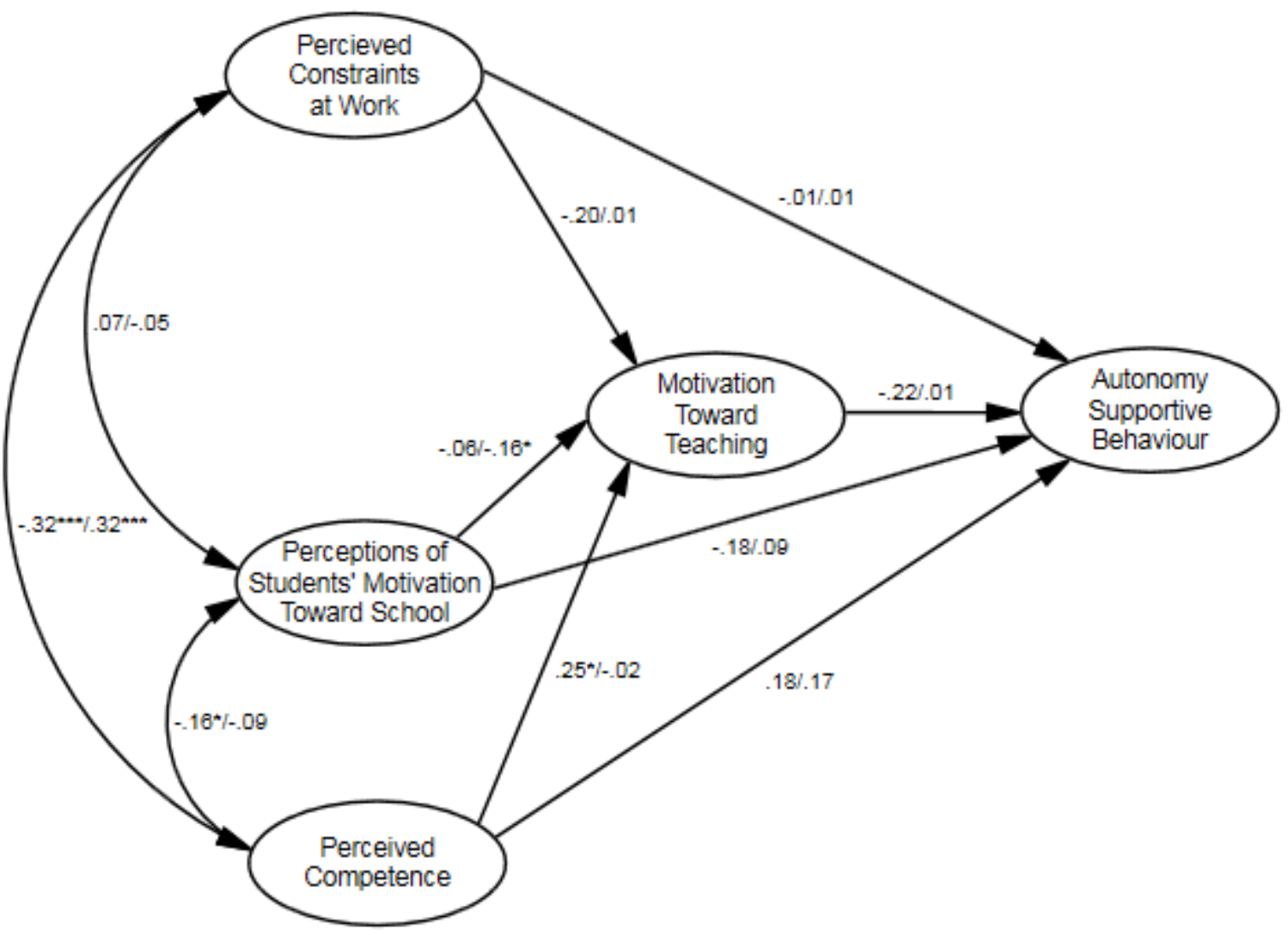

Fig. 7 Comparison of partially mediated model using final modified and original scales for TAs

$* p<.05 ; * * p<.01 ; * * * p<.001$

Note Standardised coefficients are shown with estimates for final modified scales presented on the left and estimates for original scales presented on the right. Model also controls for gender effects on autonomous motivation for teaching and setting effects on all variables.

Final modified scale fit $=\chi^{2}(559)=839.14, p<.001 ;$ RMSEA $=.05,90 \%$ RMSEA CI $[.04, .06] ;$ CFI $=.91$

Original scale fit $=\chi^{2}(1646)=2517.20, p<.001 ;$ RMSEA $=.05,90 \%$ RMSEA CI $[.05, .05] ;$ CFI $=.86$

All figures were created in Amos (Version 21, Arbuckle and Wothke 1999).

Arbuckle, J.L., \& Wothke, W. (1999). Amos 4.1 user's guide. Chicago: Marketing Department, SPSS Inc., SmallWaters Corporation.

Note As in Figures 1-3, for the sake of simplicity, in each of these figures the word 'autonomous' has been removed twice from where the word 'motivation' appears while the phrase 'perceived competence' refers to 'perceived competence for teaching'. A '+' symbol denotes a positive relationship and a '-' symbol a negative relationship. Straight single-headed arrows represent hypothesised causal paths, while doubled-headed arrows are hypothesised correlations. 